U.S. Department of Energy,

Richland Operations Office

\title{
Investigation of the Tritium Release from Building 324 in Which the Stack Tritium Sampler Was Off, April 14-17, 1998
}

Issued: June 1998

May 6 - June 6, 1998 


\section{RELEASE AUTHORIZATION}

Document Number: DOE/RL-98-45, Revision 0

Investigation of The Tritium Release From Building

Document Title: $\quad 324$ In Which The Stack Tritium Sampler Was Off, April 14-17, 1998

This document, reviewed in accordance with DOE Order 1430.1D, "Scientific and Technical Information Management," and DOE G 1430.1D-1, "Guide to the Management of Scientific and Technical Information," does not contain classified or . sensitive unclassified information and is:

\section{APPROVED FOR PUBLIC RELEASE}

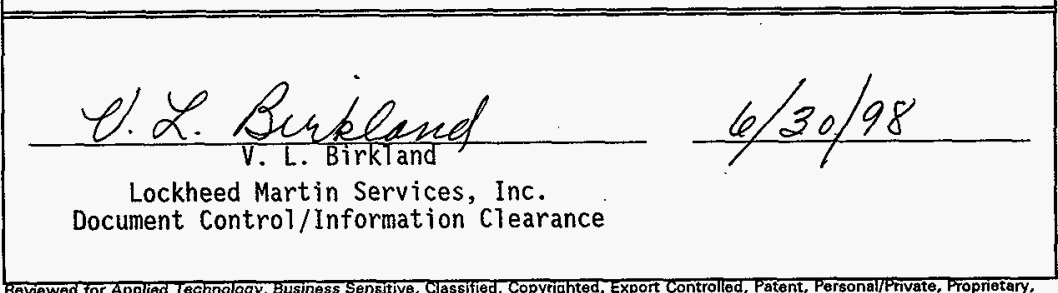

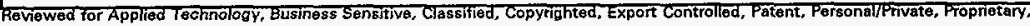
Protected CRADA, Tradomark, Unclassified Controlled Nuclear Information.

Trademark Disclaimer. Reference herein to any specific commercial product, process, or service by trade name, tredemark. manufacturer, or otherwise, does not necessarily constitute or imply its endorsement, recommendation, ar favoring by the United States Govemment or any agency thereof or its contractors or subcontractors. The views and opinions of authors expressed herein do not necessarily state or reflect those of the United States Government or any agency thereat. This repart has bean reproduced from the best available copy.

Printed in the United States of Americe.

Available to the U.S. Department of Energy and its contractore from the U.S. Department of Energy Otfice of Sclentific and Technical Information, P.O. Box 62, Oak Ridge, TN 37831: Telephone: 423/576-8401.

Available to the public from the U.S. Departmert of Commerce National Technical information Service, 5285 Port Royal Road, Springfield, VA 22161: Telephone: 703/487-4650. 


\section{Executive Summary}

\section{The Event}

On April 14, 1998, a Pacific Northwest National Laboratory (PNNL) researcher performing work in the Building 324 facility approached facility management and asked if facility management could turn off the tritium sampler in the main exhaust stack. The researcher was demonstrating the feasibility of treating components from dismantled nuclear weapons in a device called a plasma arc furnace and was concerned that the sampler would compromise classified information. B\&W Hanford Company (BWHC) operated the facility, and PNNL conducted research as a tenant in the facility. The treatment of 200 components in the furnace would result in the release of up to about 20 curies of tritium through the facility stack. The exact quantity of tritium was calculated from the manufacturing data for the weapons components and was known to be less than 20 curies. The Notice of Construction (NOC) approved by the Washington State Department of Health (WDOH) had been modified to allow releasing 20 curies of tritium through the stack in support of this research. However, there were irregularities in the way the NOC modification was processed.

The researcher was concerned that data from the sampler could be used to back-calculate the tritium content of the components, revealing classified information about the design of nuclear weapons. He had discussed this with the PNNL security organization, and they had told him that data from the sampler would be classified. He was also concerned that if he could not proceed with operation of the plasma arc furnace, the furnace would be damaged.

The researcher told BWHC management that the last time the furnace was shut down and restarted it had cost $\$ 0.5$ million and caused a six month delay in the project's schedule. He had already begun heating up the furnace before recognizing the security problem and was concerned that stopping the heatup could damage the furnace. The NOC that allowed the research did not have an explicit requirement to operate the sampler during a release. The sampler was installed several years previously for other research.

After reviewing the NOC and other safety basis documents, and after consulting environmental compliance specialists, facility management agreed to turn off the sampler. Before doing so however, they contacted the RL Facility Representative. The Facility Representative discussed the action with his management and with the RL program manager responsible for the Building 324 facility. This occurred after regular working hours, and some organizations that should have been involved in this type of decision were not contacted.

BWHC and RL employees and managers reviewed the regulatory requirements for sampling and were convinced that their actions were acceptable and in compliance with 
the regulations. ${ }^{1}$ However, none of the participants considered how the act would appear to either peripheral workers or the public who did not have knowledge of the regulatory requirements. The RL representatives saw no reason to stop the action, and they allowed BWHC to proceed with turning off the sampler. The components were treated with the sampler turned off, and the sampler was returned to service following the test.

Later, some unknown individuals called several external organizations, including WDOH to report what appeared to be a serious breach of public trust. The sampler had run for several years when no tritium was released during work. When work was finally performed that released tritium, the sampler was turned off just before the release and restarted after the release. Several newspapers heard about this and made inquiries with RL. The RL Manager was taken by surprise because he had not been told that nuclear weapons components were being treated on the Hanford Site.

In order to verify that the quantity of tritium released during the research was within the limits of the NOC, WDOH requested that one of their representatives with a security clearance be allowed to review the classified manufacturing data. This request was rejected by RL on the grounds that WDOH did not have a "need-to-know" for access to this classified information. This judgement was based in part on the fact that WDOH was provided with an unclassified document stating that none of the 200 components could exceed a tritium content of 100 millicuries. RL's position reminded external organizations of the type of secrecy that had prevailed at the Hanford Site years ago, when predecessor agencies had released quantities of radioactive material on surrounding communities without their knowledge.

After first rejecting the request for access to the data, $R L$ reversed its position and provided the classified data to WDOH. WDOH reviewed the data and found that the released quantity was within the limitation of the NOC. However, WDOH still considered that RL had violated other requirements of the Washington Administrative Code (WAC). WDOH subsequently submitted to RL a Notice of Violation.

On May 6, 1998, the Richland Operations Office Manager directed that the event be investigated. The investigation was to evaluate the sequence of events to identify causes and lessons learned.

\section{Potential Effects of the Release}

While the NOC allowed a release of 20 curies of tritium, radioactive decay after manufacture of the neutron generator tubes reduced the maximum possible quantity to no more than 8.1 curies. (The actual value is classified, but WDOH verified that it was less than 20 curies.) Tritium emits a very low energy beta particle and is not retained in the body very long. The biological effect of tritium is much lower than for similar quantities of other radionuclides that are familiar to Hanford workers. The maximum radiological effect from 20 curies to the maximally exposed individual would be $0.001 \mathrm{millirem}$.

\footnotetext{
' At the time the investigation was conducted, WDOH had issued a Notice of Violation contending that RI had violated the WAC when the sampler was turned off. It is not the purpose of this investigation to determine whether RL did or did not violate any regulations.
} 


\section{The Investigation}

The investigating team divided the event into three distinct parts and evaluated each one individually. These parts were:

- The decision to turn off the sampler,

- The NOC modification, and

- The decision to withhold classified information from the State reguiator.

The investigation team concluded that the decision to turn off the sampler was inappropriate, primarily because it failed to take into account the perception it would create among peripheral workers and the public. The NOC modification was executed improperly because it was not approved by the correct authorities and did not state that testing involved parts from dismantled nuclear weapons. Also, the decision to withhold the classified information was incorrect because the WDOH representative had the necessary security clearance and was required by the WAC to verify RL's compliance with specific regulations.

\section{The Root Causes}

The investigating team found that the root cause of the decision to turn off the sampler was that a concern for cost and schedule risk led managers to proceed with work without involving all necessary authorities. The BWHC managers who made the decision to turn off the sampler looked diligently for a way to prevent the potential loss described by the researcher. While this reflected a positive attitude toward stewardship of the taxpayer's resources, it led to several errors.

After reviewing the regulatory requirements, the BWHC managers and $\mathrm{RL}$ representatives concluded that turning off the sampler was'allowed by the NOC, was within the bounds of the regulations, and was otherwise acceptable. They made the decision after regular business hours and under considerable cost and schedule pressure. Consequently, they did not involve all appropriate authorities in the decision. In particular, they did not involve Fluor Daniel Hanford Company, nor the RL

Environmental Assurance; Permits, and Policy Division (RL-EAP). They did not discuss the proposal with WDOH. Such discussions are a normal part of the regulatory process. Also, they did not consider the appearance of the act to peripheral workers and the public.

The root cause of the NOC modification errors was that there was no formal Hanford process for management of NOCs. PNNL personnel initiated the NOC modification even though they had no authority for regulatory permitting at the Building 324 facility. After obtaining WDOH approval, they obtained an approval signature from the RL Science and Technology Operations Division (RL-STO), but RL-STO also had no authority for Building 324 permitting. PNNL never obtained approval from RL-EAP, although there was a space for an RL-EAP signature on the document. The RL Functions, Responsibilities, and Authorities Manual states that only RL-EAP has authority for regulatory permitting. The investigation team concluded that if there was a formal procedure for PNNL to follow, the modification would probably have been processed by the proper authorities and would probably have more clearly defined the NOC's scope and restrictions. 
The root cause of the denial of access for the State regulator was that there was no documented Hanford process for establishing need-to-know for access to classified information. The question of need-to-know was directed to the RL Science and Technology Programs Division (RL-STP) Classification Officer. He believed that some unclassified information provided previously to WDOH was sufficient for their requirements. However, he did not adequately understand the regulator's responsibility to verify information and did not refer the issue to the holder of the data - the Albuquerque Operations Office (AL). When RL finally approached AL, AL approved providing the classified information so that it could be given to WDOH.

\section{Contributing Causes}

The investigation also identified several contributing causes. The most important of these were:

- The RL directive on readiness assessments failed to include a DOE Order requirement that should have prompted consideration of a readiness assessment for this test. A readiness assessment for the test might have prevented the problem.

- PNNL lacked an adequate process for control and oversight of their research on the Hanford Site in non-PNNL facilities.

- The RL internal communications process did not function to assure that senior management was aware of sensitive work performed on site.

\section{Recommendations}

The investigation team made recommendations to correct the causes of the event, as well as to address several related issues. Some of these recommendations were:

- $R L$ and its contractors should review the facts and causes of this event with appropriate personnel. The review should emphasize the importance of assuring that only the correct authorities approve documents or authorize actions. The review should also emphasize the importance of assuring that worker and public perception is taken into account when resolving health, safety, and environmental issues.

- RL should issue a directive that describes the process for managing Notices of Construction.

- $\mathrm{RL}$ should issue a directive, or modify an existing directive, to describe the process for establishing need-to-know for access to classified information. 


\section{Table of Contents}

Executive Summary .......................................................................................................................... $\mathrm{V}$

The Event $\quad v$

Potential Effects of the Release vi

The Investigation $\quad$ vi

The Root Causes vii

Contributing Causes viii

Recommendations viii

Table of Contents ....................................................................................................................... ix

1. Background and Scope.......................................................................................................... 1

A. Background 1

B. Scope 2

C. Team Participants 2

II. Facts Determined During the Investigation ....................................................................... 3

A. Sequence of Events 3

Plasma Arc Furnace NOC Approved . 3

Building 324 Facility Transferred from PNNL to BWHC 3

The Plasma Arc Furnace Changes Direction 4

Tritium Monitoring and Sampling History 6

Plasma Arc Furnace Problems $\quad 8$

A New PI Assigned $\quad 8$

Completion of the "Prep and Risk" Form

Failed to Identify Public Sensitivity 9

Plasma Arc Furnace Ready to Treat Neutron Generator Tubes 9

Furnace Heatup for the Test Begins 10

The PNNL PI Asks BWHC to Turn off the Sampler 10

Contractor Personnel Meet with RL to Discuss PNNL's Request 11

The Test Proceeds $\quad 12$

WDOH Denied Access to Classified Information $\quad 12$

Senior Management Not Informed 15

The Media and External Organizations Inquire 15 
B. Other Facts

1. PNNL Assessments Previously Identified

Some Contributing Causes of the Event

2. Problems with Readiness Assessment Requirements

3. One Employee Files a Formal Concern

4. Biological and Environmental Effects of

Tritium Are Small Compared to Other Radionuclides

Properties and Hazards of Tritium

Use of Tritium in Consumer Products

5. The PNNL "Prep and Risk" Form Question on

"High Public Awareness" Issues Did Not Prompt

Correct Response

6. Some Believed Public Information Should Have Been Considered

7. Authority for Establishing Need-to-Know for Access to

Classified Data Lies with the Possessor of the Data

III. Analysis

A. Causes

1. Summary of Causes

a. The Decision to Turn Off the Tritium Sampler

b. The NOC Modification Errors

c. The Decision to Withhold Information from the State Regulator

2. Causes of the Decision to Turn Off the Tritium Sampler

a. Root Cause

b. Contributing Causes

3. Causes of the NOC Modification Errors

a. Root Cause 
b. Contributing Causes

4. Causes of the Decision to Withhold Information from the State Regulator

a. Root Cause

b. Contributing Causes

B. Discussion of Causal Sequence

1. Analysis: Conditions

2. Analysis: Causal Sequence

C. Evaluation of the Employee Concerns Process

Figure III-1 - Event and Causal Factors Chart

Figure III-2 - MORT Fault Tree Analysis

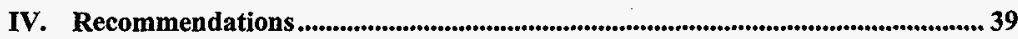

A. Recommendations for $\mathbf{R L}$ and Contractors 39

B. Recommendations for $\mathbf{R L} \quad 39$

C. Recommendations for PNNL $\quad 40$

D. Recommendations for FDH 41

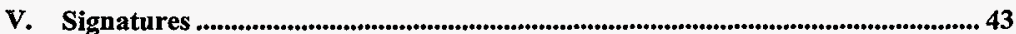

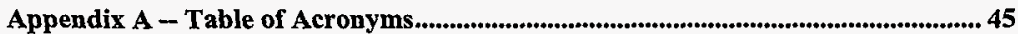




\section{Background and Scope}

\section{A. Background}

On April 14, 1998, a PNNL researcher performing work in the Building 324 facility approached facility management and asked if they could turn off the tritium sampler in the main exhaust stack. The researcher was demonstrating the feasibility of treating components from dismantled nuclear weapons in a device called a plasma arc furnace and was concerned that the sampler would compromise classified information. The facility was operated by $\mathrm{BWHC}$, and $\mathrm{PNNL}^{2}$ was conducting research as a tenant in the facility. RL had an NOC approved by WDOH that allowed releasing tritium, but there were irregularities in the NOC approval.

Before turning off the sampler, facility management contacted RL. The RL representatives allowed $\mathrm{BWHC}$ to proceed with turning off the sampler. The sampler was turned off while the tritium was released and was then returned to service.

Later, an unknown person or persons called several external organizations, including WDOH, to report what appeared to be a serious breach of public trust. The sampler had run for years when no tritium work was performed. Finally, when some tritium work was performed, the sampler was turned off during the release. Several newspapers heard about this and began to inquire with RL. The Manager, RL, was taken by surprise because he had not been told that nuclear weapons components were being treated on the Hanford Site.

In order to verify that the quantity of tritium released during the research was within the limits of the NOC, WDOH requested that one of their representatives with a security clearance be allowed to review the classified manufacturing data. This request was rejected by $\mathrm{RL}$ on the grounds that WDOH did not have a "need-to-know" for this information.

After turning down the request for access to the data, $\mathrm{RL}$ later reversed its position and provided the data to WDOH. WDOH reviewed the data, but still considered that RL had violated the WAC. WDOH subsequently submitted to RL a Notice of Violation (NOV).

2 The Battelle Memorial Institute is the contractor that operates the Pacific Northwest National Laboratory for the U. S. Department of Energy. 
The RL Operations Office Manager was concerned about how this event had occurred and directed that it be investigated ${ }^{3}$.

\section{B. Scope}

The investigation team reviewed documents and interviewed personnel to determine the sequence of events that led to the event. It also determined:

- How the decision was made to turn off the sampler and what procedures governed this type of decision,

- If procedural requirements were followed,

- The root causes and lessons learned from management system breakdowns, and

- The appropriateness of the decision to deny WDOH officials access to classified data.

The investigation did not attempt to deal directly with regulatory issues because these are presently under discussion between WDOH and RL.

The investigation team divided the event into three distinct parts and examined each one as a separate issue. The three parts were:

- The decision to turn off the tritium sampler,

- The NOC modification, and

- The decision to withhold classified information from the State regulator.

\section{Team Participants}

David H. Brown of the Performance Assessment Division led the investigation team. Other participants were Kerry M. Schierman of the Waste Operations Division, W. Don Seaborg of the Site Operations Division, and Charles R. Delannoy of the Performance Assessment Division.

${ }^{3} \mathrm{RL}$ memorandum, John D. Wagoner to David H. Brown, Investigation of Event at Building 324 in which Stack Monitors Were Turned Off, 98-PAD-030, dated May 10, 1998 


\section{Facts Determined During the Investigation}

\section{A. Sequence of Events}

\section{Plasma Arc Furnace NOC Approved}

In 1992, PNNL began development of a plasma arc furnace as part of the Mixed Waste Focus Area (MWFA) program. This was to demonstrate the feasibility of treating low level and transuranic radioactive mixed wastes. The furnace used an electric arc in a graphite crucible to provide thermal energy to melt and vitrify feed materials fed into the furnace melt chamber. On April 18, 1996, WDOH approved an NOC for the project ${ }^{4}$. The project was to be conducted by PNNL in the Building 324 facility, which was then operated by PNNL.

The NOC stated that the furnace would be used to provide engineering data to evaluate the performance of the treatment system as well as to provide fate data for various waste species. A DC potential was to be applied between a graphite crucible and an electrode, resulting in a stable arc between the crucible contents and the electrode. Waste materials were to be fed into the melt chamber by either a bulk or large object feeding system. The NOC stated that process waste would contain $\mathrm{Pu}-238, \mathrm{Pu}-239, \mathrm{Pu}-240, \mathrm{Pu}-241, \mathrm{Pu}-242$, Am-241, U-234, U-235, U-238, Sr-90, and Cs-137. The source term was based on performing approximately 20 tests over a three-year period. The NOC stated that the system was being developed to treat wastes from across the DOE complex. However, it was not specific in describing the form of the waste. The cover letter transmitting the NOC to WDOH described the waste as buried waste from across the DOE complex.

\section{Building 324 Facility Transferred from PNNL to BWHC}

On November 1, 1996, DOE transferred responsibility for operation of the Building 324 facility from PNNL to Fluor Daniel Hanford Company (FDH). BWHC was to operate the facility for FDH as it was prepared for eventual decontamination and

${ }^{4}$ Radioactive Air Pollutants Notice of Construction for Plasma Arc Furnace Operation, Waste Technology Engineering Laboratory, 324 Building, 300 Area, Hanford Site, dated April 18, 1996 
decommissioning. RL and BWHC managers told the investigation team that the transfer occurred on relatively short notice. As a result, some management systems were not fully functional. For example, PNNL did not provide procedures to cover all equipment operations. There was also confusion about responsibilities and authorities among PNNL, FDH, BWHC, RL-AMT, and RL-AMF.

PNNL was to continue some work in the facility. Therefore, PNNL and BWHC executed a facility use agreement (FUA) ${ }^{5}$ which specified relative duties and responsibilities between PNNL and BWHC. The FUA specified that the authorization/safety basis (including the safety analysis reports, USQD logs, facility procedures, facility permits, and effluent monitoring plans), ownership, and maintenance were all transferred to BWHC.

A "retained premises" clause in the FUA allowed PNNL to use portions of the building for continued research, provided they kept the Building Manager informed of work activities they were conducting. The BWHC Building Manager was to review and concur on all procedures used by PNNL for work in the facility. The review and concurrence verified the necessary and sufficient application of standards for conduct of operations, radiological control, and quality assurance, as well as other standards and requirements of FDH and/or BWHC. The plasma arc furnace was located within a PNNL retained area.

The FUA stated that responsibility for regulatory permitting was transferred from PNNL to BWHC, but this conflicted with another document called the "Transfer Agreement." The Transfer Agreement stated that FDH and BWHC only assumed responsibility for environmental compliance issues related to certain Hanford cleanup regulatory agreements.

\section{The Plasma Arc Furnace Changes Direction}

In early 1997, some of the customers for the plasma arc furnace project found other, less expensive methods for treating mixed waste. PNNL and DOE changed the focus of the plasma arc furnace project to treating neutron generator tubes from the Pantex Plant in Amarillo, Texas. The neutron generator tubes were not considered waste, but were components from dismantled nuclear weapons. Treating the neutron generator tubes in the furnace would render the previously classified components unclassified and "demilitarized." The neutron generator tubes contained tritium, all of which would be released when the tubes were treated. PNNL project management recognized the need to change the NOC to include the new tritium effluent waste stream.

${ }^{5}$ Facility Use Agreement, approved by Battelle Memorial Institute, B\&W Hanford Company, Fluor Daniel Hanford, Inc., and the U. S. Department of Energy,

October 31, 1996

${ }^{6}$ Transfer Agreement, approved by the U. S. Department of Energy, Fluor Daniel Hanford, Inc., and the Battelle Memorial Institute, dated October 31, 1996 
The initial test of the treatment process was to vitrify 200 neutron generator tubes in the plasma arc furnace. The actual tritium content of the tubes is part of the design of the weapons and is classified, but the total quantity for all 200 tubes at the time of manufacture could not exceed 20 curies. Because of radioactive decay of the tritium from the time of manufacture, RL-STP. calculated that the total content of the 200 neutron generator tubes that the Pantex Plant provided to PNNL could not have exceeded 8.1 curies. $^{\text {? }}$

On June 19, 1997, a PNNL environmental specialist contacted WDOH and notified them that PNNL wanted to change the NOC by adding "approximately 20 curies" of tritium to the source term. This was to support a new vitrification test. The new vitrification test was the treatment of the neutron generator tubes. The new radionuclide would increase the project's "potential to emit" radiation exposure by 0.001 millirem which is the change in exposure to the maximally exposed individual over a one-year period. The maximally exposed individual was located 1,400 meters northeast of the stack. The original NOC found that the maximally exposed individual could receive an annual unabated dose of 26 millirem. The WAC requires continuous sampling for individual radionuclides during emissions if the "potential to emit" of a radionuclide exceeded $10 \%$ of the total unabated "potential to emit" exposure for the building exhaust:

The PNNL environmental specialist documented his discussion in a proposed modification to the NOC. ${ }^{8}$ Because the change was minor, the document referred to the change as a modification and not a revision. He attempted to obtain RL concurrence on the document, but the two RL individuals he expected to sign it were on leave. He then asked WDOH to sign the NOC modification first, and they did. This was a deviation from convention, wherein all DOE signatures were normally obtained before approaching WDOH. WDOH approved the NOC modification on August 9, 1997.

The NOC modification did not state that the target feed stock was changed from waste to dismantled weapon parts. It also did not address emissions sampling, although the modification did not appear to affect the sampling requirements in the original NOC. '

${ }^{7}$ The values of 20 curies and 8.1 curies are only bounding values for the design and actual tritium content of the neutron generator tubes. The design and actual values are classified and less than these values.

${ }^{8}$ Modification to the Annual Possession Quantity, Plasma Arc Furnace, Located in the 324 Building, approved by WDOH on August 9, 1997

${ }^{9}$ The original NOC stated that sampling requirements were to be in accordance with 40 CFR 61. RL and WDOH are presently discussing whether these requirements were followed. It is outside the scope of this investigation to determine whether RL violated the regulatory requirements. 
PNNL next submitted the NOC modification to the RL-STO environmental engineer who signed it on September 24, 1997. Although PNNL provided an approval signature line for RL-EAP, PNNL never obtained an RL-EAP approval. The PNNL environmental specialist who processed the NOC modification told the investigation team that he faxed the document to RL-EAP twice, but never got a response. The cognizant RL-EAP representative told the investigation team that he never saw the fax.

The RL Functions, Requirements, and Authorities Matrix (FRAM) identified RL-EAP as the only functional authority for NOC maintenance and for negotiating with environmental regulatory agencies. However, the RL-EAP air permitting specialist said that contractors and RL line organizations take the lead on NOC modifications because his time is spent actively involved in the development and negotiation of air operating permits. He said that NOC modifications are made frequently and he did not have time to personally manage each one.

The RL signature blocks on the NOC modification listed individual contributors as signatories. The individual contributor from RL-STO actually signed the document more than a month after WDOH signed it, but the RL-EAP space was left blank. The RL-EAP individual contributor identified on the NOC modification told the investigation team that he customarily signs documents like this. However, in neither case had signature authority been delegated to individual contributors from the respective division directors. Division directors from both RL-EAP and RL-STO told the investigation team that the document should have been signed by director-level managers.

Neither FDH, RL-TPD, nor RL-STP were consulted during the NOC modification process. The PNNL environmental permitting specialist said that he discussed the NOC modification with BWHC and/or WMH, but no one in BWHC or WMH interviewed by the investigation team recalled the discussion. ${ }^{10}$

\section{Tritium Monitoring and Sampling History}

A tritium monitor and a tritium sampler were installed for the 324 stack in Building 324A in 1991 to support research on tritium targets for the New Production Reactor Program. Building $324 \mathrm{~A}$ was a small structure adjacent to the Building 324 stack. This program ended in 1993. Later, an isokinetic monitoring system, which included separate features to monitor tritium and other building emissions, was installed in Building 324D. Building 324D was another, newer structure located near the Building 324 main stack. At that time, the tritium sampler in Building 324A was moved to Building 324D and the original $324 \mathrm{~A}$ tritium monitor was permanently removed from service. Since the tritium

${ }^{10}$ The investigation team was not surprised at the difference in recollections between the PNNL environmental permitting specialist and the BWHC/WMH personnel. The discussion would have been relatively routine, and nearly a year passed before the investigation interview. 
target research was cancelled and no other research operations specifically required tritium monitoring, the tritium feature of the isokinetic monitor in Building $324 \mathrm{D}$ was never calibrated or placed in service.

When operating, the tritium monitor continuously measures the stack exhaust for the concentration of tritium and provides an alarm at a specified high level. The isokinetic monitoring system consists of a vacuum pump drawing stack exhaust past a series of probes, which can be calibrated for tritium readouts. The tritium sampler continuously collects samples from the effluent stream and processes them so they can be analyzed for tritium content.

The primary function of the tritium monitor is to provide operators with the tritium content of the stack effluent on a real-time basis. The primary function of the tritium sampler is to provide a record of tritium discharged during operations.

The section of the Building 324 Safety Analysis Report (SAR) which addressed operations ${ }^{11}$ stated that the 324 Building exhaust stack is continuously sampled and monitored to ensure assessment and documentation of emissions. It further states that the stack exhaust is continuously monitored for the concentration of tritium. Within the same section, however, it states that the tritium monitoring and continuous tritium sampling systems are used only when research operations require it. A table contained within the same section includes a note that also states that tritium sampling and monitoring are only performed when required for research operations. The SAR does not contain any technical safety requirement or operating safety requirement for operating either the tritium sampler or the tritium monitor.

The section of the Building 324 Facility Effluent Monitoring Plan (FEMP) ${ }^{12}$ that described the effluent monitoring systems ${ }^{13}$ stated that both continuous sampling and continuous monitoring for tritium were occurring. However, the section of the FEMP describing sampling requirements ${ }^{14}$ did not specify any specific tritium sampling or monitoring requirements. It did state that all radionuclides anticipated to contribute greater than $10 \%$ of the emission dose from the sampled emission point shall be accounted for, either by direct analysis or by inference from an indicator measurement. (The emission dose from the tritium was much less than $10 \%$ of the emission dose from other Building 324 work.)

${ }^{11}$ HNF-SD-SPJ-SAR-001, 324 Building Safety Analysis Report, Section 4, Design of the Facility and Description of Operations

12 PNL-MA-660, Facility Effluent Monitoring Plan for the 324 Facility, dated November, 1994

${ }^{13}$ Section 7.0, Characteristics of Current Effluent Monitoring Systems

${ }^{14}$ Section 6.0, Effluent Monitoring/Sampling System Requirements 
When BWHC accepted operational control of the 324 facility in November 1996, the tritium sampler was continuously operating, but no tritium monitor was operating. The BWHC environmental specialist for the Building 324 facility told the investigation team that BWHC did not consider any tritium monitoring or sampling was required. They intended to maintain the sampler in operation until authorization basis documents were changed to state clearly that tritium monitoring and sampling were not required.

\section{Plasma Arc Furnace Problems}

In April and July of 1997, PNNL conducted testing of the plasma arc furnace with nonradioactive material. However, the furnace drain tube did not function adequately in the April 1997 test, and the furnace did not drain properly. As a result, the glass mixture was left in the furnace and it solidified.

In July 1997 , the furnace was started using a contingency procedure to compensate for the presence of the solidified material. The test ran for several days before the furnace began to function improperly. After the test, PNNL found that the liner and refractory were seriously damaged. The damage was attributed to the extended time for startup using the contingency procedure, and the presence of various chemicals within the glass mixture. The PNNL project personnel told the investigation team that modification and repair cost approximately $\$ 0.5$ million and had a six month impact on the project's schedule. However, PNNL did not consider preparing an occurrence report despite the value basis reporting requirement of DOE M 232.1-1 ${ }^{15}$. Section 7, Value Basis Reporting, specifies that damage to equipment in excess of $\$ 10,000$ is to be reported as an off-normal occurrence.

Prior to performing the 1997 tests, the PNNL project manager completed a PNNL "Prep and Risk" form. The PNNL Project Manager and the PNNL Product Line Manager approved the form. Completion of the form was required by the PNNL Standards Based Management System. The electronic "Prep and Risk" form consisted of 61 questions that classify project parameters and prompt consideration of hazards. Neither PNNL nor BWHC considered performing a pre-operational readiness assessment.

\section{A New PI Assigned}

On October 1, 1997, PNNL assigned a new researcher, or Principal Investigator (PI), to the plasma arc furnace project. This was done when the previous PI left PNNL on entrepreneurial leave. By November 1997, the new PI had issued a project management plan to address processing neutron generator tubes in the furnace.

${ }^{15}$ DOE M 232.1-1, Occurrence Reporting and Processing of Operations Information 


\section{Completion of the "Prep and Risk" Form Failed to Identify Public Sensitivity}

In November 1997, the project issued a new "Prep and Risk" form to address testing with actual neutron generator tubes. The completed form acknowledged the release of tritium but contained at least one possible error. The project answered "no" to question no. 44, which read in part, "Will the project involve...processes... of high public awareness that have the potential to harm Battelle's image...? Examples include...weapons development or enhancement." Even though this project did not address weapons development or enhancement, the fact that components from dismantled weapons were being destroyed and tritium was being released should have alerted PNNL to public perception issues. The public interest that followed the release demonstrated that this work had the potential to harm Battelle's image.

\section{Plasma Arc Furnace Ready to Treat Neutron Generator Tubes}

In March 1998, the plasma arc furnace had been rebuilt and was again operational. This included the installation of a new drain tube assembly. The PNNL project manager and PI briefed the RL-EAP team leader on their intention to process neutron generators in the furnace. During the briefing, PNNL discussed security and regulatory issues. At this time the PI was aware that no tritium monitoring was being performed, but was not aware BWHC was still operating the tritium sampling system. He had inquired about tritium monitoring, but did not understand the distinction from tritium sampling. For this reason, the PI did not recognize the security issues associated with the stack sampler.

On March 30, 1998 the BWHC senior project manager for the Building 324 facility called a meeting with PNNL project managers so that they could explain the plasma arc furnace operations to Building 324 facility personnel. The BWHC Building Manager told the investigation team that PNNL had been keeping BWHC informed of progress on preparing for the test with the neutron generator tubes. However, PNNL was nearly ready for the test, and BWHC management wanted to assure that the preparations were in order. The meeting included participants from PNNL, BWHC, and the RL-SOD Facility Representative.

During the meeting, BWHC pointed out the need for an unreviewed safety question (USQ) evaluation. The purpose of the USQ evaluation was to assure that the work was consistent with the accident analyses in the authorization basis documents. PNNL had performed a USQ evaluation during February 1998, but they did not use the BWHC procedure and format. ${ }^{16}$

On April 9, 1998, BWHC and PNNL documented the USQ evaluation using PNNL's analysis and BWHC's procedure. ${ }^{17}$ The USQ evaluation determined that operations were

\footnotetext{
${ }^{16}$ PNNL USQ Evaluation 324-PNNL-1988-01S

${ }^{17}$ BWHC USQ Evaluation 324-BWHC-98-022
} 
bounded by the existing requirements and accident analyses. Tritium monitoring and sampling were not explicitly addressed in the USQ evaluation document, although this did not indicate an oversight or error.

Also on April 9, 1998 BWHC notified PNNL that an ALARA review meeting would be necessary before the test could begin. They scheduled a meeting for April 13, 1998. The purpose of the ALARA review was to determine if all reasonable steps were taken to minimize radiation exposure. Someone from the Building 324 facility health physics organization had told PNNL that no ALARA review meeting was required, but that individual was not authorized to make that determination. Because of the discussion with the health physics technician, the PI was under the impression that an ALARA review was not required.

The ALARA review was conducted the afternoon of April 13, 1998 by the BWHC Enhanced ALARA Committee and PNNL. During the review, BWHC personnel mentioned the presence of the tritium sampler to PNNL project personnel, but no one recognized the security issue at that time. BWHC approved the radiation work permit (RWP) at about 1600 on April 13, 1998.

\section{Furnace Heatup for the Test Begins}

At about 2300 on April 13, 1998 the PNNL PI started the furnace heatup. No radioactive material was introduced into the furnace at this time.

At about 0830 on April 14, 1998, the furnace was heated up and processing nonradioactive feed in preparation for the neutron generator tubes. It was at this time that the PNNL PI recognized the potential security implications associated with stack sampling. Specifically, if the total tritium emission was known (together with other, unclassified information), the tritium content of the neutron generators could be calculated. The tritium content of the neutron generators was a design feature of nuclear weapons that was classified. The PI contacted the PNNL safeguards and security organization (PNNL-SASS) to discuss the issue. Approximately one hour later PNNLSASS staff confirmed with the PI that there was a security issue. PNNL-SASS then began to research options, such as controlling the stack sampler and associated data as classified information.

\section{The PNNL PI Asks BWHC to Turn off the Sampler}

Meanwhile, the PI contacted the BWHC effluents cognizant engineer, notified him of the potential conflict, and asked if the sampler could be turned off. The PI stated his concern about the need for timeliness in achieving resolution to the issue. The current test run called for introducing the neutron generator tubes containing tritium into the furnace at about 2300 that evening. The PI also expressed his concern about repeating the problems during the previous furnace runs in 1997. He told the cognizant engineer about the six month delay and the approximate $\$ 0.5 \mathrm{M}$ cost that the project had experienced previously, probably because of extending the period of the heatup. 
The BWHC cognizant engineer reviewed the FEMP and NOC and could not find a requirement to maintain the sampler in operation. At about noon he contacted the BWHC Environmental Compliance Officer (ECO) to obtain his concurrence to turn off the tritium sampler. The ECO performed his own requirement review as well as obtaining an interpretation from a Waste Management Hanford Company (WMH) effluent specialist. WMH provides environmental consultation and support to BWHC. Both agreed that tritium sampling was not required by the facility SAR, FEMP, or NOC.

They attempted to contact the FDH effluent specialist to discuss the matter with him, but were unable to locate him. The BWHC ECO then asked the PI if the furnace run could be postponed or delayed until the following day when the appropriate notifications and approvals could be obtained. The PI again expressed concern that a delay could result in damage to the furnace. This would cause a further delay and cost to repair the damage. (The PI told the investigation team that he was willing to cancel the furnace run if stack tritium sampling was required by the 324 facility and appropriate security compensation measures could not be established in time.)

No consideration was given at this time to contacting the PNNL environmental specialists who had processed the NOC. Also, no consideration was given to performing another USQ evaluation for turning off the sampler. At 1530, the BWHC effluent specialist sent an e-mail message to the Building 324 facility HPTs instructing them to prepare to "valve out" the stack tritium sampling system. The message included a discussion of the justification for turning off the sampler. The effluent specialist had discussed the plan earlier with the HPTs, but the HPTs requested that the instruction be provided in writing. $B W H C$ facility management told the investigation team that it was not unusual for the HPTs in Building 324 to request their instructions in writing. The HPTs were employees of $\mathrm{FDH}$, rather than BWHC.

\section{Contractor Personnel Meet with RL to Discuss PNNL's Request}

The BWHC ECO considered it appropriate to inform RL of their decision prior to taking action. The BWHC Building Manager instructed the HPTs to wait until they could brief RL. At about 1600 , an informal meeting was convened in the RL-SOD Facility Representative's office. The meeting included the RL-TPD program manager, the RLSOD Facility Representative, the PNNL PI, the BWHC ECO, the BWHC building manager, the HPT supervisor and the BWHC effluent specialist. (While the meeting convened at about 1600, some participants did not arrive until after 1630.) The RL-SOD environmental specialist was called and participated by speaker phone. The participants did not consider involving RL-STP or RL-STO, although RL-STO had signed the NOC and NOC modification.

The PNNL PI again expressed his concern about interupting the test to these participants, mentioning the six month delay and \$0.5 million cost that the project had experienced before. The meeting participants all reviewed and discussed the NOC, the FEMP, and the SAR. Upon completion of the review, the three participating RL personnel agreed 
that turning off the sampler would not violate the NOC, the FEMP, or the SAR. They also discussed the negligible biological effect that the release could have.

At about 1700, another e-mail message directed the HPT supervisor to "valve out" the tritium sampler. The HPT supervisor checked for agreement among the meeting participants that this action was acceptable. Although a procedure did not exist to perform the operation, the HPT and HPT supervisor removed the sampler from service using their knowledge of the system.

At about this same time the PNNL PI notified PNNL-SASS that the tritium sampler would be removed from service and that they no longer needed to pursue alternatives. PNNL-SASS had been evaluating alternatives such as protecting data during and after the acquisition process. Each of the alternatives would have required procedures and training that would have introduced enough delay to jepordize the project.

The RL Facility Representative and the RL-TPD program manager tried unsuccessfully to contact the RL-TPD Division Director and inform him of what was occurring. At about 1700, they contacted the RL Assistant Manager for Facility Transition (RL-AMF) and notified him of the situation. RL-AMF accepted their explanation, but directed them to notify WDOH that they were proceeding with operating the plasma arc furnace. RLAMF wanted them to notify WDOH because there had been a long delay between the time the NOC modification had been approved and its use. He did not specifically intend that they discuss the tritium sampler with WDOH.

The RL-TPD program manager called the WDOH manger responsible for Hanford oversight in Olympia, but it was after normal business hours. The program manager left a message on an answering machine in which he stated that the plasma arc furnace operations with radioactive material were to begin that night. The RL-SOD environmental specialist attempted to notify the air permitting specialist in RL-EAP but he was on vacation. She succeeded in contacting the RL-EAP backup point of contact, but the backup specialist had no knowledge of the facility or NOC specifics.

\section{The Test Proceeds}

At 1000 on April 15, 1998, the test run to process the neutron generator tubes began. It was completed successfully on April 17, 1998, after processing exactly 200 tubes. At 1400 on April 17, 1998, BWHC returned the Building 324 stack tritium sampler to service. BWHC personnel told the investigation team that they returned the sampler to service for consistency with the configuration described in the SAR. However, they did not place the tritium monitor in service.

\section{WDOH Denied Access to Classified Information}

On April 17, 1998 the PNNL project manager informed the RL-STP project manager there had been an issue with the sampler generating classified information, but the issue had been resolved by removing the sampler from service. On the same day, PNNL 
informed WDOH that they were planning to process 4,000 more neutron generator tubes ${ }^{18}$. They told WDOH that they would discuss this at the next routine monthly meeting. This meeting was scheduled for April 21, 1998.

At the April 21, 1998 monthly meeting, PNNL notified WDOH that they had successfully processed the 200 neutron generator tubes between April 14 and April 17, 1998. They also told WDOH that the facility had stopped tritium sampling for the operation because of security requirements. The WDOH representative reacted to this and asked to see the data on the tritium content of the neutron generator tubes. He was told the manufacturing data was maintained by the Pantex Plant and was not available on the Hanford Site. The WDOH representative told the investigation team that he asked the RL-EAP representative who was at the meeting to obtain the data for him. He wanted to see it at a special meeting scheduled for April 28, 1998. The RL-EAP representative told the investigation team that she believed she was only asked to make security arrangements for additional staff to review the data. Therefore, she took no action to obtain the data.

On April 23, 1998, WDOH performed an inspection of the Building 324 facility. WDOH evaluated the plasma arc furnace and air monitoring equipment. They also reviewed documentation regarding the NOC requirements and conditions. The next day, the inspectors called BWHC and WMH and told them that WDOH was considering issuing an NOV.

Also on April 23, the PNNL PI notified the BWHC ECO that PNNL-SASS had determined that PNNL, lacked the authority to release the classified tritium data; only RL was authorized to release it. The ECO notified the FDH environmental specialist who in turn notified RL-EAP. RL-EAP notified the RL-STP Classification Officer of a potential issue and the Classification Officer notified the Safeguards and Security Division (RLSAS). No one took any further actions to obtain the tritium data until April 27, 1998, when RL, BWHC, FDH, and PNNL conducted a dry run for the April 28, 1998 meeting.

At the dry run, the PNNL PI recognized that no one was making preparations to provide WDOH with the classified manufacturing data. He brought this to the attention of those present at the dry run. After the meeting, the RL-STO environmental engineer and the RL-TPD program manager spoke with the RL-STP Classification Officer and requested that he determine whether they could provide the classified data to WDOH.

The RL-STP Classification Officer saw that the NOC authorized a total release of 20 curies, and that PNNL had established with the Pantex Plant that the total release could

${ }^{18}$ The additional test run with 4,000 more tubes was to demonstrate that the process could run for an extended period of time. Once this demonstration was complete, the Pantex Plant would consider building a production scale furnace. However, the PNNL project was terminated before the last test run could be performed. 
not have exceeded 20 curies. This was documented in an unclassified letter from $\mathrm{AL}^{19}$ that had already been given to WDOH. After discussing the issue with RL-SAS, the Classification Officer concluded that WDOH did not have a need-to-know for access to the specific manufacturing data for the neutron generator tubes. He did not contact AL which had authority over the data. The actual data was only at Sandia National Laboratory, and AL had responsibility for management of Sandia within DOE. The data itself was not required for the research at PNNL, and PNNL never had it in their possession.

The RL-STP Classification Officer met with the RL-STP Division Director and informed her of his conclusion, which she accepted. However, neither the RL-STP Division Director nor the Classification Officer understood that WDOH was making the trip from Olympia simply to inspect the data. Therefore, they did not attempt to notify WDOH or RL-EAP that RL-STP intended to deny WDOH access to the classified manufacturing data during the April 28, 1998 meeting. Later, in a telephone conversation between the Classification Officer and the RL-TPD program manager, the program manager said he believed that WDOH did have a need-to-know for access to the manufacturing records. However, this did not cause the Classification Officer to change his mind.

At the meeting on April 28, the RL-STP Classification Officer told WDOH that it could not have access to the data because it lacked a need-to-know for this information. WDOH repeated the request to see the data, citing the specific regulation that required DOE to provide it. The RL-STP Classification Officer repeated his position. The WDOH representative stated that WDOH would issue an NOV for withholding data, turning off what WDOH considered to be a required tritium sampler, and performing operations not identified in the NOC.

When the meeting with WDOH adjourned, RL representatives met together and discussed the need to provide the data to WDOH. The consensus among the RL representatives was that WDOH was entitled to see it because of the requirements in the WAC describing WDOH's responsibilities. That evening, the RL-TPD Division Director called the WDOH representative at home and told him that $R L$ would make arrangements to allow him access to the classified manufacturing data.

On April 29, 1998, the RL Assistant Manager for Science and Technology (RL-AMT) was told of the results of the meeting with the WDOH representative. (The division directors of RL-STP, RL-STO, and RL-SAS all report to RL-AMT.) Before this time, he had no knowledge of this issue, and had not even been told that nuclear weapons components were being processed on the Hanford Site. He directed the RL-STP Classification Officer to contact AL to request that WDOH be given access to the classified data. After an explanation of the situation, AL granted the authority for

${ }^{19}$ DOE Amarillo Area Office letter, Jerry S. Johnson to Michael J. Connolly, Lockheed Martin Idaho Technologies Company, Mixed Waste Focus Area, "Request for Mixed Waste Focus Area Support," dated August 5, 1997 
WDOH to have access. RL directed PNNL to request this information from Sandia National Laboratory, who had the original manufacturing data. A classified summary of the data was provided to RL through PNNL.

\section{Senior Management Not Informed}

Prior to April 29, 1998, RL-AMT staff and division directors had not told senior management that components from dismantled nuclear weapons were being treated on the Hanford Site. In a weekly status report dated March 9, 1998, the RL-STP division submitted an item to RL-AMT stating that PNNL was cooperating with the Pantex Plant contractor to demonstrate a technology to dispose of nuclear weapons components. This report did not state that the components were being treated at the Hanford Site. A reader unfamiliar with the project could have inferred that the test was scheduled to occur at the Pantex Plant. RL-STP issued a similar report on April 20, 1998 which identified Building 324 as the location of the test, but this report was issued after the event had already occurred.

\section{The Media and External Organizations Inquire}

At some time prior to April 30, 1998, a representative of the Government Accountability Project (GAP) called DOE-HQ to discuss the tritium sampling issue. He had been called by one or more Hanford workers and been told that the sampler was turned off during the release. At least two individuals had also called several newspapers, WDOH, and one or more Oregon State regulatory agencies. On April 30, 1998, the Division Director, RLSTP responded to GAP, DOE-HQ and newspaper inquiries. On May 5, 1998, articles about the event appeared in both Tri-Cities and Portland, Oregon newspapers.

On May 6, 1998, RL conducted another meeting with WDOH in which RL provided the classified data to WDOH. On May 13, 1998, WDOH issued an NOV with two findings which specified:

- During operation of the plasma arc furnace, the building 324 stack tritium sampler was turned off; violating the regulatory requirement for confirmatory sampling to verify low emissions of tritium.

- The project to treat components from dismantled nuclear weapons violated the NOC for the plasma arc furnace. 


\section{B. Other Facts}

\section{PNNL Assessments Previously Identified Some Contributing Causes of the Event}

On September 17, 1997, PNNL issued a self-assessment that identified several weaknesses associated with the implementation of environment, safety, and health requirements on PNNL projects. This included the need for improving:

- Pre-operational assessments and

- Control and oversight of work performed outside of PNNL facilities.

The investigation team discussed the self-assessment and management response with cognizant managers in PNNL and RL. The cognizant managers showed the investigation team evidence that PNNL was working to improve pre-operational readiness assessment activities. However, because of this event, they recognized that they did not have adequate control and oversight of research activities on the Hanford Site which are performed in facilities operated by other contractors.

\section{Problems with Readiness Assessment Requirements}

PNNL and RL managers told the investigation team that they expected the project to perform some kind of pre-operational readiness activity before beginning the vitrification test. This would have been more than completing a PNNL "Prep and Risk" form and should have identified issues like the conflict with security requirements. It should not only have assessed the readiness of the project, but also the readiness of the facility for the test. However, there was no PNNL procedure describing this process. There was a PNNL procedure for Readiness Assessments and Operational Readiness Reviews ${ }^{20}$, as described in DOE Order $5480.31^{21}$, but the PNNL procedure and the DOE order referred to assessments required by DOE. It did not address pre-operational assessments performed purely to address PNNL's needs.

DOE $0425.1,{ }^{22}$ when properly implemented requires contractors to evaluate the need for performing a readiness assessment for restarts of program work within an operating

${ }^{20}$ PNL-MA-97, Operational Readiness Review System

${ }^{21}$ DOE Order 5480.31, Startup and Restart of Nuclear Facilities

${ }^{22}$ DOE 0425.1 , Startup and Restart of Nuclear Facilities, is intended to supercede DOE Order 5480.31 . 
facility. This applies to program work restarts when DOE approval is not required for changes to authorization basis limits or requirements. This is in section 2.a.(2) of Attachment 1, "Contractor Requirements Document." DOE 0425.1 allows contractors to apply the graded approach when defining the scope of a readiness assessment, and DOE involvement may not be required. Starting the plasma arc furnace test was a program work restart item as described in the Contractor Requirements Document.

RL issued RL Implementation Directive (RLID) 425.1 to describe how to satisfy the requirements of DOE $O 425.1$. It was written in a manner suggesting that if the RLD was followed correctly, contractors would not need to use DOE O 425.1. However, RLID 425.1 failed to implement the specific requirement of section 2.a.(2) of DOE O 425.1 .

DOE O 425.1 and RLID 425.1 were not specified in either the FDH or PNNL contracts. However, FDH identified them as standards they would follow in the Building 324 Standards/Requirements Identification Documents (S/RIDs). Therefore, BWHC was to implement these directives at the time of the test.

The order and the contractor requirements document were issued in September 1995, while the RLID was issued in September 1996. A representative of the RL Quality, Safety, and Health Programs division told the investigation team that RL experienced delays in incorporating these directives into its contracts. The delays occurred because of differences of opinion within RL about how to identify specific requirements to incorporate in the contracts. In January 1998, RL directed each contractor to evaluate both the order and RLID to assure that the new directives carried over all necessary requirements from the superceded directives. RL requested a reply by June 1998 . RL would provide instructions on implementing the directives after evaluating the results of the contractors' reviews.

\section{One Employee Files a Formal Concern}

On May 18, 1998, a PNNL employee who participated in the vitrification test filed a concern with the PNNL Staff Concerns Program. He had gone on vacation immediately after the test and returned to news of the controversy. He believed initially that the sampling equipment which was turned off was located in the work area for monitoring employee exposure. He was specifically concerned that he may have received excessive radiological exposure from the test.

The PNNL Staff Concerns Office contacted the cognizant line manager and project manager. They reviewed the PNNL employee's concern with PNNL safety and health specialists. A routine bioassay for tritium had been performed for the employee immediately after the test. The results of the bioassay, together with the worker's potential exposure, were evaluated and communicated to the employee. The manager of the PNNL Staff Concerns Program told the investigation team that the employee was satisfied with the way he was treated and was no longer concerned that he had received excessive exposure. 
Aside from the PNNL employee discussed above, no other employees filed concerns. However, two or more individuals called the news media and some external organizations. The investigation team discussed the Hanford Site employee concerns programs with responsible managers from RL, FDH, and PNNL. All of them said that their programs were aggressive in providing a way for workers to raise safety and health concerns without fear of retaliation. They said that performance measures for their programs showed that they were successful in satisfying concerned employees in many cases, and the rate at which concerns were reported had not increased recently. However, they all said that there are some employees who will not use the system before contacting the media or other outside organizations, regardless of how good or credible the system is.

The FDH employee concerns manager said that she received a number of concerns at the time that Building 324 was transferred from PNNL to BWHC, but she was not receiving any now. She also said that she knew of no other recent cases where employees reported health, safety, or environmental concerns to external organizations.

\section{Biological and Environmental Effects of Tritium Are Small Compared to Other Radionuclides}

\section{Properties and Hazards of Tritium}

Tritium is a low energy, pure beta emitting radionuclide with a physical half-life of 12.5 years. Its beta particle has a maximum energy of $18.6 \mathrm{keV}$ and a mean energy $5.7 \mathrm{keV}$. This is about $1 / 120$ th the energy of Sr-90 or Y-90 per disintegration. Tritium is eliminated from the body with an average biological half-life of about 10 days in adults. The low decay energy of tritium generally requires that tritium must be taken into the body before any radiological damage can occur. Under normal circumstances, tritium does not present an external radiation hazard. When tritium is taken into the body as tritiated water or tritiated hydrogen gas, it tends to be dispersed throughout the whole body, the same as the normal water of the body tissues.

Because of its low beta energy, its dilution throughout all of the soft tissues, and short biological half life, tritium has an extremely low radiological toxicity when compared to other beta emitters. Its toxicity is very low when compared with similar quantities of other radionuclides familiar to Hanford workers, such as strontium-90, yttrium-90, phosphorous-32, iodine-131, or cesium-137.

\section{Use of Tritium in Consumer Products}

Tritium is commonly used in consumer products, most notably wrist watches and emergency exit signs. Aircraft exit signs typically contain approximately 3 curies of tritium while commercial exit markers can contain up to 25 curies of tritium. The estimated radiological dose to individuals is considered essentially zero due to the 
containment materials absorbing the weak beta particles and the fact that there is no intimate contact with the tritium in these devices.

\section{The PNNL "Prep and Risk" Form Question on "High Public Awareness" Issues Did Not Prompt Correct Response}

The PNNL "Prep and Risk" form is governed by the procedure, "Risk Management," in the "Project Management" subject area of the PNNL Standards Based Management System (SBMS). The form itself is completed and routed electronically. The project manager completes the form, although he may have an investigator on his staff prepare a draft. The product line manager then approves the form.

Question 44 of the "Prep and Risk" form requires the preparer to determine if the project causes a risk to Battelle's reputation or result in activist group activities directed against the project, staff, or Battelle. If the preparer checks "yes," the form directs him or her to the following instructions:

"Precautions such as including disclaimers in the contract, involving stakeholders, or obtaining independent reviews may be required to protect Battelle from such risks. Contact PNL 'Legal' for specific guidance." (Emphasis added)

While this instruction addressed involving stakeholders, it did not direct the user to consult PNNL public involvement specialists. Instead, it directed the user to the PNNL Legal Department. The PNNL public involvement specialists' role is to assist PNNL management in identifying activities that should include public information or involvement as part of the planning process.

In the case of the "Prep and Risk" form for the neutron generator tube test of the plasmá arc furnace, Question 44 was answered incorrectly. The form was checked "no," but subsequent events have shown that the correct answer was "yes." Therefore, the project never got to the stage of the process where it would contact either the Legal Department or a public involvement specialist to consider informing or involving stakeholders during the planning process.

As noted previously, PNNL did not consider conducting an independent review of the test, such as a pre-operational assessment.

\section{Some Believed Public Information Should Have Been Considered}

The investigation team interviewed representatives from $R L$ and PNNL who coordinate interface activities with the Hanford Advisory Board (HAB). The investigation team also interviewed several members of the HAB. 
The RL and PNNL coordinators noted that some HAB members might have been interested to learn of an activity working with tritium during project planning. The $H A B$ is an important part of the process for sharing information and achieving public involvement in Hanford activities. The RL and PNNL coordinators spoke with the investigation team and stated that tritium had acquired considerable public attention since the summer of 1997. This was caused by the consideration that was given to starting up the Fast Flux Test Facility (FFTF) for the purpose of producing tritium and medical isotopes. That proposal led to protest demonstrations in the Tri-Cities and in other cities around the Pacific Northwest. Regardless of the potential health effects from the Building 324 tritium release, and regardless of the regulatory permitting, the coordinators said the simple fact that the project involved tritium could easily lead to a need for some form of public information.

The investigation team did not interview a representative sample of the $\mathrm{HAB}$ membership, and some members may well want more projects (such as the plasma arc furnace) described for them during planning. However, for the most part, the members who talked to the investigation team were concerned that a focus on small projects could distract the $\mathrm{HAB}$ from focusing on the whole Hanford cleanup. One member said that WDOH, not the $\mathrm{HAB}$, is the public's defense for assuring that Hanford activities are conducted safely with respect to air releases. Another said that the issue in this event was not the nature of the project itself but the public trust issue associated with turning the sampler off.

The RL and PNNL coordinators provided the investigation team a copy of an information booklet intended to guide managers in identifying issues requiring public involvement. The booklet was entitled, "Public Involvement Desk Reference," and was originated by the RL Office of External Affairs (RL-OEA). It had been distributed to RL managers, but had not yet been widely distributed among the RL contractors.

The Public Involvement Desk Reference included a checklist that managers could use to identify projects requiring public involvement. The checklist began with the statement, "If you answer yes to any of the following questions, contact RL-OEA for leadership, coordination and facilitation of public activities." The checklist did not include any questions that would have necessarily led the user to a definitive conclusion that public involvement was required for the plasma arc furnace. However, several questions could have prompted an inquiry with RL-OEA. A statement at the end of the checklist read, "Your issue or activity not listed? Contact RL-OEA to help determine your needs." RLOEA public involvement personnel serve as a resource to help identify issues of concern or potential controversy to line managers.

The investigation team also discussed the HAB's expectation with the RL-STP Division Director and the PNNL project manager for the plasma arc furnace. Both said that they did not believe that a project this small would have been of interest to the HAB. In making this judgement, they considered that the actual environmental and health hazard from the tritium was inconsequential, and that the particular weapons components were not explosive or otherwise dangerous. 
The RL-STP Division Director said that she participated on the Site Technology Coordination Group, which included several stakeholder representatives from the HAB. She was familiar with the checklist in the Public Involvement Desk Reference and believed that she understood what issues required public involvement. Both she and the PNNL project manager said they were unaware that increased public sensitivity to tritium work associated with the possible restart of the FFTF should have led them to consider notifying the $\mathrm{HAB}$ regarding the plasma arc furnace.

\section{Authority for Establishing Need-to-Know for Access to Classified Data Lies with the Possessor of the Data}

The RL-SAS Division Director told the investigation team that need-to-know issues are often referred to the Classification Officer. However, the appropriate authority for determining need-to-know lies with the organization that is holding the data. In the case of the manufacturing data for the neutron generator tubes, that was Sandia National Laboratory and AL. The data was never in PNNL's possession, and RL only had the data when it was obtained to finally provide it to $\mathrm{WDOH}$.

There is no procedure that describes the correct process for establishing need-to-know. The RL-SAS Division Director said that the two primary documents which establish need-to-know requirements for DOE are DOE M 471.2-1A, "Classified Matter Protection and Control" and Executive Order 12958. DOE M 471.2-1A provides no explicit direction regarding who has final authority to resolve need-to-know issues. Executive Order 12958 states that need-to-know "means a determination made by an authorized holder of classified information that a prospective recipient requires access to specific classified information in order to perform or assist in a lawful and authorized governmental function.,"23 (Emphasis added.)

The Classification Officer told the investigation team that Executive Order 12958 applies to National Security Information, while the classified data associated with the plasma arc furnace test was Restricted Data. The discussion in the executive order was only important as a guide in generally understanding how to apply the concept of need-toknow authorization.

${ }^{23}$ Executive Order 12958, Part 4 - "Safeguarding," Section 4.1.(c), "Need-to-know" 


\section{Analysis}

\section{A. Causes}

\section{Summary of Causes}

The investigation team used the Management and Oversight Risk Tree (MORT) fault tree analysis as well as event and causal factors analysis to develop conclusions from the facts. These analytical techniques were used to judge the adequacy of management systems to prevent this event. Parenthetical statements directly following both root and contributing causes correlate with the MORT chart ${ }^{24}$.

The analysis divided the event into three parts and analyzed each part separately. This was done because these parts of the event occurred independently, and the investigation team judged that the results would be most valuable if each part was evaluated separately. The three parts were:

- The decision to turn the tritium sampler off,

- The NOC modification, and

- The decision to withhold classified information from the State regulator.

The investigation team concluded that the decision to turn the sampler off was inappropriate, primarily because it failed to take into account the perception it would create among peripheral workers and the public. ${ }^{25}$ The NOC modification was executed improperly because it was not signed by the correct authorities and did not identify the change in feed stock. Also, the decision to withhold the classified information was incorrect because the WDOH representative had the necessary security clearance and was required by the WAC to verify $R L$ 's compliance with specific regulations.

24 The investigation team used the DOE MORT table developed by the Idaho National Engineering Laboratory, System Safety Development Center, dated November, 1994.

${ }^{25}$ At the time the investigation was conducted, WDOH had issued an NOV contending that RL had violated the WAC when the sampler was turned off. It is not the purpose of this investigation to evaluate whether RL did or did not violate any regulations. 
The causes are summarized below. A detailed discussion of each root and contributing cause is provided in sections III.A.2, III.A.3, and III.A.4.

\section{a. The Decision to Turn Off the Tritium Sampler}

The root cause of the decision to turn off the tritium sampler was: A concern for cost and schedule risk led managers to proceed with work without involving all necessary authorities. (MORT:..Supervisory judgement less than adequate)

\section{Contributing causes were:}

- RL did not require contractors to fully implement readiness assessment requirements of DOE O 425.1. (MORT: Did not use barriers; System design and development less than adequate)

- Coordination between all responsible and interested authorities was inadequate. (MORT: Interdepartmental coordination less than adequate)

- PNNL did not properly use its "Risk and Prep" process to consider an independent or pre-operational assessment. (MORT: Did not use barriers)

- Communications with the external regulatory authority were inadequate. (MORT: External communications less than adequate)

- RL senior management was not informed that components from dismantled nuclear weapons were being treated at the Hanford Site. (MORT: Internal communications less than adequate)

- PNNL lacked a process for exercising appropriate control and oversight of research activities in non-PNNL facilities on the Hanford Site. (MORT: System design and development plan less than adequate )

- Adequate configuration control was not maintained on the FEMP and the SAR. (MORT: Configuration control less than adequate)

\section{b. The NOC Modification Errors}

The root cause of the NOC modification errors was: There was no formal Hanford process for management of NOCs. (MORT: System design and development plan less than adequate)

\section{Contributing causes were:}

- The wrong contractor and RL organizations processed and approved the NOC modification. (MORT: Task assignment less than adequate; Internal communications less than adequate) 
- RL-EAP did not have sufficient personnel resources to follow all air permitting issues. (MORT: Support services resources less than adequate)

- External documents were signed by individual contributors without signature authority delegation. (MORT: Task assignment less than adequate)

- RL personnel did not follow the requirements of the FRAM. (MORT: Policy implementation less than adequate)

\section{c. The Decision to Withhold Information from the State Regulator}

The root cause of the decision to withhold information from the State regulator was: There was no documented Hanford process for establishing need-to-know for access to classified information. (MORT: System design and development plan less than adequate)

\section{Contributing causes were:}

- The wrong organization made the need-to-know determination. (Task assignment less than adequate)

- An understanding of the State regulator's statutory responsibility and authority was not communicated to the person who made the need-to-know determination. (MORT: Internal communication less than adequate)

- RL Management did not adequately review the staff recommendation before allowing the regulator's access to be denied. (MORT: Supervisory judgement less than adequate)

\section{Causes of the Decision to Turn Off the Tritium Sampler}

\section{a. Root Cause}

The root cause of the decision to turn off the tritium sampler was: A concern for cost and schedule risk led managers to proceed with work without involving all necessary authorities. (MORT: Supervisory judgement less than adequate)

Discussion: When the RL and BWHC managers and permitting specialists were presented with the request to turn the tritium sampler off, they looked diligently for a way to justify supporting PNNL's project. While this reflected a commendable 
attitude toward stewardship of the government's resources, the high priority of this desire led to the following inappropriate actions and errors:

- The participants did not think through either the public or the worker perception of the decision.

- The decision was made after regular working hours when most participants were expecting to soon go home.

- The participants were unable to contact the correct authority in RL-EAP and went ahead without his concurrence.

- The participants did not contact the State regulatory authority to discuss the issue with them.

- The participants were unable to contact the correct authority in FDH and went ahead without his concurrence. This was done even though FDH is the company contracted by $\mathrm{RL}$ for operation of the Building 324 facility.

- The participants did not contact either RL-STP or RL-STO and went ahead without their concurrence.

Had the participants confirmed their analysis with the proper authorities, it is likely that these individuals would have recognized all of the issues and/or would have involved the State regulatory authority in the decision.

\section{b. Contributing Causes}

RL did not require contractors to fully implement readiness assessment requirements of DOE O 425.1. (MORT: Did not use barriers; System design and development less than adequate)

Neither DOE O 425.1 nor RLID 425.1 was specified in the contracts of either PNNL or FDH, although DOE O 425.1 was issued in September 1995. However, the S/RIDs document for the Building 324 facility specified that both directives were applicable for Building 324 activities. While these standards were identified for compliance, RLD 425.1 failed to implement the requirement of DOE 0425.1 to evaluate project startup activities for use of the contractor's readiness assessment process.

RL and PNNL managers said they had an expectation that PNNL project personnel would perform some form of pre-operational assessment to assure that the project and the facility were both ready to begin the test. However, there was no explicit PNNL requirement or procedure for such an activity. Even a readiness assessment of limited scope would have significantly increased the probability of identifying the conflict between the sampler and the security requirement at an early date. This conclusion is based on the fact that even a brief ALARA review was sufficient to expose the issue. 
If the PNNL and FDH contracts required them to implement DOE O 425.1, and if RLID 425.1 correctly implemented the requirements of DOE O 425.1, then PNNL and/or BWHC would have been required to evaluate the plasma arc furnace test for the need for a readiness assessment. Considering the cost and schedule risks as well as the regulatory requirements associated with the project, a graded readiness assessment would have been a reasonable result of an evaluation. It is also reasonable to believe that a readiness assessment of limited scope would have identified the conflict with the security requirement. Because of the graded approach considerations described in the order, PNNL could have performed a simple readiness assessment without $R L$ approval or participation.

\section{Coordination between all responsible and interested authorities was inadequate. (MORT: Interdepartmental coordination less than adequate)}

When managers and permitting specialists from the Building 324 operating contractor met with RL, they were unable to contact representatives from RL-EAP or FDH. They were also unable to contact the Director of RL-TPD. No attempt was made to contact representatives from RL-STO or RL-STP. Each of these parties had some responsibility for compliance with the NOC and the regulations. The participants made the decision to proceed with turning the sampler off without coordinating the decision with these authorities.

\section{PNNL did not properly use its "Prep and Risk" process to consider an independent or pre-operational assessment. (MORT: Did not use barriers)}

When the PNNL project personnel completed the "Prep and Risk" form, they answered Question 44 "no" when the correct answer was probably "yes." Question 44 asked if the project created risk from "high public awareness" activities that could reflect negatively on Battelle's reputation. After the test, PNNL and the Hanford Site received considerable negative attention. This question on the "Prep and Risk" form was a barrier to negative effects of the event that was not used.

If the item was marked "yes" the form would have required the project to consider performing an independent review. This review could correspond with the preoperational assessments discussed in PNNL's self-assessment of November 1997, and with readiness assessments as described in DOE $\mathrm{O} 425.1$. It is likely that such an assessment would have identified the security conflict early enough to resolve it properly.

Question 44 would also have required the project to consider informing tribal nations and stakeholders, such as members of the Hanford Advisory Board. The Hanford Advisory Board includes representatives from stakeholder groups, including WDOH. A dialog with the $\mathrm{HAB}$ would have considered the negligible environmental effect of the release and allowed WDOH to assure themselves that the work was within the scope of the NOC. However, it was not clear to the investigation team whether or not 
the size and hazard of the plasma arc furnace project warranted public involvement beyond that of the normal NOC process.

Communications with the external regulatory authority were inadequate. (MORT: External communications less than adequate)

When managers and permitting specialists from the Building 324 operating contractor and DOE decided to proceed with turning the sampler off, they did not consult with the State regulatory authority on this issue. However, a fundamental principle for consistently achieving regulatory compliance is constant dialogue with the regulators.

RL senior management was not informed that components from dismantled nuclear weapons were being treated at the Hanford Site. (MORT: Internal communications less than adequate)

RL-STP did not inform RL-AMT that radioactive components from dismantled nuclear weapons were being treated at the Hanford Site until after the event. Because RL-AMT was not informed, he did not inform RL-MGR. This was important information because of the sensitive nature of this work. The lack of knowledge prevented senior management from asking the questions necessary to assure themselves that the work was being conducted properly. For example, the lack of knowledge prevented RL-MGR and RL-AMT from asking if PNNL would perform a readiness assessment.

PNNL lacked a process for exercising appropriate control and oversight of research activities in non-PNNL facilities on the Hanford Site. (MORT: System design and development plan less than adequate)

PNNL has been improving their processes for exercising oversight of research activities within PNNL facilities and for activities off the Hanford Site. However, they have not been adequately attentive to activities in Hanford non-PNNL facilities. For the plasma arc furnace, there was not sufficient oversight to prompt a reasonable assessment of the readiness of the equipment to operate within the Building 324 facility.

Before the Building 324 facility was transferred to BWHC, PNNL employees managed the building. Therefore, building management and researchers used common procedures and operated in the same culture. The Building Manager had a good understanding of the strengths and weaknesses in the knowledge and behavior of researchers and so could exercise more informed oversight of research work. When the facility is managed by another company, PNNL must exercise a different type of control to assure that their work is conducted correctly. 
Adequate configuration control was not maintained on the FEMP and the SAR. (MORT: Configuration control less than adequate)

The FEMP and the SAR both stated that stack tritium monitoring equipment was installed and operating, even though stack tritium monitoring equipment had not operated for several years. This lack of attention to the accuracy of the two documents contributed to an inappropriate attitude toward their content. The State regulatory authority considered statements in the FEMP to constitute a baseline understanding of the facility's effluent monitoring program. However, facility personnel considered that most of the content was simply information that may or may not be current.

\section{Causes of the NOC Modification Errors}

a. Root Cause

The root cause of the NOC modification errors was: There was no formal Hanford process for management of NOCs. (MORT: System design and development plan less than adequate)

If there had been a formal process for modifying the NOC, it is reasonable to believe that it would have required the preparer to identify any changes to the process that the modification was allowing. It would therefore have identified the fact that the plasma arc furnace would now be used to treat components from dismantled nuclear weapons rather than buried waste. The.State regulatory authority would then be fully aware of the process that RL and its contractors believed was addressed by the NOC.

A formal process would also describe the required concurrence and approval sequence. It would prohibit either RL or a contractor from submitting an NOC modification to the State regulatory authority without first obtaining formal approval from RL-EAP and the correct RL line organization. This would provide assurance that all required concurrences and approvals were obtained before activities were conducted under the NOC.

\section{b. Contributing Causes}

The wrong contractor and RL organizations processed and approved the NOC modification. (MORT: Task assignment less than adequate; Internal communications less than adequate)

The modification to the NOC was negotiated and processed by PNNL, but PNNL had no authority over the NOC. RL, rather than PNNL, should have obtained WDOH approval on the NOC modification. The facility operator, BWHC, was not involved in this action. The Facility Use Agreement assigned responsibility for permitting issues to the facility operator, although the Transfer Agreement may have placed this responsibility on PNNL. When the NOC modification was submitted to RL, RL- 
STO, rather than RL-TPD approved it. RL-TPD was not involved and not aware of the action. Also, RL-EAP never approved the NOC modification. The RL FRAM states that RL-EAP is responsible for negotiations with the regulators and maintaining permits.

RL-EAP did not have sufficient personnel resources to follow all air permitting issues. (MORT: Support services resources less than adequate)

RL-EAP had only one individual fully able to follow air permitting issues. The individual was on leave at the time when the NOC modification was transmitted to RL-EAP for approval. He was also on leave the day the decision was made to turn off the sampler. He had too many responsibilities and apparently overlooked the modification on two occasions. (RL-EAP management assigned another individual to follow air permitting issues. However, this individual must undergo additional training and orientation before being allowed to assume full responsibility in his position.)

External documents were signed by individual contributors without signature authority delegation. (MORT: Task assignment less than adequate)

The NOC modification was signed by an individual contributor from RL-STO, and PNNL expected an individual contributor in RL-EAP to sign it as well. PNNL's expectation was based on the fact that individual contributors in RL-EAP signed these documents in the past. The respective division directors were unaware of the NOC modification before the event. The directors of RL-EAP and RL-STO told the investigation team that their policy was that external documents are to be signed at the division director level or higher. Had the division directors been required to sign the modification, they would have had the opportunity to ask questions and assure themselves that NOC requirements were being followed correctly.

\section{RL personnel did not follow the requirements of the FRAM. (MORT: Policy implementation less than adequate)}

The RL FRAM specifies that only RL-EAP is authorized to prepare, coordinate, and submit permit applications. It also states that only RL-EAP is authorized to consult and negotiate with the regulators on environmental permitting issues. For this NOC modification, RL-EAP did not serve these functions. If there was a stronger expectation within RL that each division follow the requirements of the FRAM, RLEAP would have negotiated the NOC modification with WDOH and processed the NOC modification document. 


\section{Causes of the Decision to Withhold Information from the State Regulator}

\section{a. Root Cause}

The root cause of the decision to withhold information from the State regulator was: There was no documented Hanford process for establishing need-to-know for access to classified information. (MORT: System design and development plan less than adequate)

Had there been a documented process for resolving need-to-know issues, the question about WDOH's access to classified data would have been coordinated with the holders of the data - Sandia National Laboratory and the Albuquerque Operations Office. AL recognized the regulatory authority's need-to-know for the information.

\section{b. Contributing Causes}

The wrong organization made the need-to-know determination (Task assignment less than adequate)

The need-to-know determination was made by RL-STP. AL or Sandia National Laboratory should have been involved in the determination.

An understanding of the State regulator's statutory responsibility and authority was not communicated to the person who made the need-to-know determination. (MORT: Internal communication less than adequate)

The RL-STP Classification Officer did not work directly with environmental regulations and did not fully understand the State regulator's authority and responsibility. For example, he did not understand the responsibility and authority of the regulator to verify information provided to him. This led the Classification Officer to incorrectly conclude that the regulator lacked the need-to-know for access to the classified data. No one in RL recognized this weakness, and so no one communicated the requirement to him.

RL Management did not adequately review the staff recommendation before allowing the regulator's access to be denied. (MORT: Supervisory judgement less than adequate)

When the RL-STP Classification Officer concluded that the State regulatory authority did not have a need-to-know for access to the data, he provided his conclusion to the RL-STP Division Director. The Division Director did not balance the recommendation of the Classification Officer with her understanding of the regulator's authority. She also did not assure that other responsible managers, such as RL-TPD, RL-EAP, and RL-AMT were aware of her decision. She then allowed the 
Classification Officer to inform the regulator that $\mathrm{RL}$ was denying him access to the data.

\section{B. Discussion of Causal Sequence}

\section{Analysis: Conditions}

The following conditions prevailed during the period of this event:

- There was no formal Hanford process for managing NOCs.

- RL organizations were not adhering closely to the roles and responsibilities defined in the FRAM.

- RL had not required contractors to implement the readiness assessment requirements of DOE 0425.1 for program activities.

- The readiness assessment requirements of DOE $O 425.1$ were not adequately implemented in RLID 425.1.

- PNNL did not have a formal process for pre-operational assessments to assure that all issues would be identified and resolved.

- There was no formalized Hanford process for resolving need-to-know issues for access to classified information.

- RL-EAP did not have enough resources to adequately perform all their air permitting responsibilities as described in the FRAM.

- The Building 324 FEMP and SAR did not accurately reflect the configuration of stack tritium monitoring equipment.

- PNNL was not exercising adequate control over activities conducted on the Hanford Site in non-PNNL facilities.

\section{Analysis: Causal Sequence}

a. The plasma arc furnace was originally permitted in April 1996. The forwarding letter that transmitted the NOC from DOE-RL to WDOH stated that the system was being developed to treat buried waste from across the DOE complex. The NOC identified various isotopes of plutonium, americium, uranium, strontium, and cesium as constituting the source term. Tritium was not listed. 
In November 1996, DOE transferred responsibility for Building 324 from PNNL to FDH. Within RL, responsibility transferred from the RL-AMT organization to the RL-AMF organization. Although responsibility for the facility transferred, PNNL was still allowed to continue research operations in "retained areas." The division of responsibility was documented in the FUA. The FUA transferred all responsibility for regulatory permitting to $\mathrm{FDH}$ and its subcontractor, BWHC. It also required PNNL to keep the BWHC Building Manager informed of all work activities.

At the time that RL transferred Building 324 to FDH and BWHC, a tritium sampler was operating continuously. A tritium monitor was installed, but had never been placed in service. Both the FEMP and the SAR included statements that both continuous sampling and continuous monitoring for tritium were being performed. This information was contained in the description section of the FEMP. The section of the FEMP that specified sampling requirements did not specify any sampling requirements for tritium. The SAR included some ambiguous language indicating either that sampling and monitoring for tritium is only required when necessary for research work involving tritium or that sampling and monitoring were conducted continuously.

This situation existed for several years, and neither the FEMP nor the SAR were corrected. These inconsistencies led to confusion regarding sampling requirements and made it difficult for personnel to make appropriate decisions during permitting activities. These problems could have been alleviated if proper configuration control was maintained on both the FEMP and the SAR.

\section{Contributing Cause: Configuration control less than adequate}

b. In April and July 1997, PNNL conducted two tests of the plasma arc furnace using nonradioactive feed material. Problems during the second test resulted in about $\$ 0.5$ million in damage and a six-month delay in the project. However, PNNL did not issue the required occurrence report to document this.

While the project manager completed a "Prep and Risk" form for the tests and completed other planning documents, a readiness assessment was not performed. The process for completing the "Prep and Risk" form did not prompt the degree of investigation necessary to identify the fact that the continuous sampler was running. It is likely that a formal readiness assessment, even one of limited scope, would have found this problem. DOE 0425.1 would have required $B W H C$ and PNNL to consider performing a readiness assessment, but $\mathrm{RL}$ was slow to require implementation.

\section{Contributing Cause: Barriers - Did not use}

c. At about this time, the project's customers lost interest in treating their waste in the plasma arc furnace. Project personnel then worked with the Pantex Plant and shifted to testing methods for treating components from dismantled nuclear weapons. 
On June 19, 1997, a representative of the PNNL Environmental Management Services organization called WDOH and obtained a verbal agreement on a modification to the NOC application. The purpose of the modification was to allow the plasma arc furnace to treat components from dismantled nuclear weapons. However, BWHC, RL-TPD, and RL-EAP were also responsible for regulatory permitting issues in Building 324. PNNL had no authority to negotiate the NOC modification.

\section{Contributing Cause: Task assignment less than adequate}

d. The PNNL representative recorded the NOC modification in a document with space for signatures by WDOH, RL-STO, and RL-EAP. Because the RL signatories were on vacation, the representative obtained the WDOH signature first, even though this is a function reserved for RL. More than a month later, an RL-STO environmental engineer signed the modification, but the RL-EAP air permitting specialist never did. Even after RL-EAP staff first saw the discrepancy in late March 1998, they did not act to correct it. The RL FRAM states that RL-EAP has responsibility for regulatory permitting activities, but RL-EAP did not participate in this permitting activity. This was partly due to the fact that RL-EAP lacked the resources to fill the air permitting specialist's duties while he was on leave.

In addition, RL policy was that external documents should be signed at the division director level or higher, unless there is explicit delegation of signature authority. This occurred because there was no formal Hanford process describing the management of NOCs.

\section{Root Cause: System design and development plan less than adequate}

\section{Contributing Causes: Task assignment less than adequate; Support services resources less than adequate}

e. In November 1997, PNNL conducted an independent assessment of the integrated environment, safety, and health management system. Among other issues, this assessment found that pre-operational assessments were not consistently performed before work started and control of work outside of PNNL facilities was weak. The investigation team found that there is no PNNL procedure governing pre-operational assessments. PNNL began corrective actions on the assessment findings, but they did not address PNNL work in non-PNNL facilities on the Hanford Site.

\section{Contributing Cause: System design and development plan less than adequate}

f. The RL-STP program manager discussed with her supervisor, the Director, RL-STP that PNNL intended to test the plasma arc furnace for use in treating components from dismantled nuclear weapons. However, this was a small part of the project manager's assignments, and she had received this assignment only a few months before the event occurred. The RL-STP Division Director did not discuss the project 
with her manager, RL-AMT. Consequently, RL-AMT never discussed it with RLMGR. RL-AMT and RL-MGR were unaware that this work was being performed: Weekly staff status reports did not explain that PNNL intended to treat nuclear weapons components on the Hanford Site.

Considering the sensitivity of treatment of radioactive nuclear weapons components at the Hanford Site, the RL internal communications system should have assured that RL-AMT and RL-MGR were aware of this activity.

\section{Contributing Cause: Internal communication less than adequate}

g. In November 1997, the PNNL project completed another "Prep and Risk" form to address testing involving actual neutron generator tubes. The project incorrectly marked the question regarding risk to Battelle's reputation as "no" when it should have been "yes." If the item were marked "yes," it would have prompted PNNL to consider performing an independent review of the test. An independent review is likely to have identified the security conflict early enough to correct it.

The "Prep and Risk" form would also have prompted the project to consider stakeholder involvement in project decision making, although it is unclear whether or not this would have been appropriate. If the project was included in the stakeholder involvement process, it could have increased public understanding of the basis for the NOC approval and involved WDOH in assuring that NOC issues were resolved.

\section{Contributing Cause: Barriers - Did not use}

h. When the plasma arc furnace project completed the "Prep and Risk" form, it did not prompt a sufficiently thorough investigation of the stack monitoring and sampling. Again, no readiness assessment was considered, but readiness assessments are a barrier to this type of event. One reason that a readiness assessment was not considered was that RL was slow to require implementation of DOE 0425.1 .

\section{Contributing cause: Barriers - Did not use}

i. Middle managers in RL and PNNL understood the project but did not understand the need to consider public involvement. They had not been told that on-site tritium work needed to be considered for public involvement, even if the scope of the work was small and the items being treated were innocuous.

\section{Contributing Cause: Internal communications less than adequate}

j. By March 1998, PNNL had completed repairs to the plasma arc furnace and was ready to treat 200 neutron generator tubes. The PNNL Principle Investigator knew that either tritium monitoring or tritium sampling would create a security issue but did not understand the distinction between the two. BWHC told him that there was no tritium monitoring, but he did not know to ask if there was also no tritium sampling. 
On March 30, 1998 PNNL project management met with BWHC facility management to discuss the upcoming test run. During this meeting, BWHC identified the need to have the PNNL USQ evaluation re-issued under BWHC procedures.

On April 9, 1998 BWHC notified PNNL that an ALARA review was required, but that it could not be conducted until April 13, 1998. April 13, 1998 was the day that furnace heatup was scheduled to begin. During the ALARA review, the Principal Investigator learned for the first time that a continuous tritium stack sampler was in operation. An arc was struck and heatup of the plasma arc furnace began that evening. The Principal Investigator was distracted by preparations for the test, and did not realize that there was a security issue until the following morning.

When the Principal Investigator had confirmed the security issue with PNNL-SASS, he asked BWHC if the stack sampler could be turned off. After reviewing the regulatory issues, BWHC facility management and the Environmental Compliance Officer met with DOE to notify them of their intention to turn the sampler off. After some discussion, representatives from RL-TPD and RL-SOD concluded that they had no objection to the action of turning the sampler off. The RL representatives contacted RL-AMF who also did not object. The meeting occurred after regular working hours, and the participants were unable to involve several authorities. These authorities were RL-EAP, who had jurisdiction over regulatory issues and the cognizant environmental compliance specialist in FDH. FDH was contracted to DOE for proper operation of the facility. It is likely that one of these organizations would have recognized the implications of turning the sampler off and either stopped the action or assured that WDOH agreed with the action. Therefore, coordination between all responsible and interested authorities was inadequate.

\section{Contributing Cause: Interdepartmental coordination less than adequate}

k. The managers and representatives who met to discuss turning the sampler off looked for a way to justify allowing the work to proceed. They were aware of the requirement to assure that activities were safe and complied with all regulatory requirements. However, they placed high priority on preventing another finaricial and schedule loss. They did not recognize the potential reaction to this action from peripheral workers and the public. Regardless of regulatory compliance or noncompliance, the act created the appearance of a serious breach of public trust. Managers exercised poor judgement in agreeing to this action.

\section{Root Cause: Supervisory judgement less than adequate}

1. In evaluating the proposal to turn off the sampler, the participants all recognized that they were evaluating an unusual regulatory issue. However, they did not attempt to contact the regulatory authority to verify that they agreed that the action was appropriate. (RL-TPD attempted to contact WDOH, but this was simply to inform them that the plasma arc furnace was about to be operated in accordance with the 
NOC.) Discussing this type of issue with the regulator is an important part of the regulatory process, but communications with the regulator were not sufficient to assure that the process would function.

\section{Contributing Cause: External communications less than adequate}

m. After the meeting, BWHC turned the sampler off and PNNL ran the test successfully. By April 21, 1998, WDOH had been informed that sampling was not performed during the test and they expressed concern. WDOH asked to see the actual source term data, although it was classified and not maintained at the Hanford Site. The WDOH representative requested that RL provide him with the data by April 28, 1998.

On April 27, 1998 the RL-STO environmental engineer and a representative from RLTPD requested the RL-STP Classification Officer to determine whether WDOH had a need-to-know for access to the source term data. The RL-STP Classification Officer reviewed the information that was presented to him and concluded that WDOH did not have a need-to-know. However, the Classification Officer was not told about WDOH's statutory responsibility and authority. In addition, the Classification Officer did not refer the issue to $\mathrm{AL}$ who had the authority for making this need-to-know determination. There is no RL procedure or other directive describing how need-toknow is determined.

\section{Root Cause: System design and development plan less than adequate}

\section{Contributing Causes: Internal communications less than adequate}

n. Later on April 27, 1998 the RL-STP Classification Officer and the RL-STO environmental engineer briefed the Division Director for RL-STP. The Division Director accepted the conclusion that WDOH should be denied access to the classified data. This was an error because WDOH had a statutory responsibility and authority to examine the data. In addition, RL-EAP was not consulted on this 
decision. RL-STP did not understand that WDOH was travelling to Richland specifically to inspect the classified data. Therefore, RL-STP did not inform RL-EAP of the decision, and no effort was made to inform WDOH.

\section{Contributing Cause: Supervisory judgement less than adequate}

At the meeting on April 28, RI informed the WDOH representative that he would not be given access to the classified data. Following the meeting, the Division Director, RLTPD called the representative at home in Olympia and notified him that $R L$ would provide access to the data. RL subsequently provided the data on May 6, 1998.

\section{Evaluation of the Employee Concerns Process}

One attribute of this event was that at least two anonymous individuals believed that it was important for them to report the event to the media and external organizations. The investigation team was interested in this because this action could indicate a breakdown of the employee concerns process in both the contractors and in $\mathrm{RL}$.

It was not the purpose of this part of the investigation to either identify the concerned employees or judge the appropriateness of their actions. Also, the investigation team avoided associating the concerned employees' actions with the problem that RL and its contractors faced with this event. The investigation team intended simply to determine if this action by the employees indicated a breakdown in the employee concerns system.

The investigation team interviewed employee concerns program managers in RL, FDH, and PNNL. In each case, the managers had performance measures that showed that a high proportion of cases are resolved in a way that satisfied the concerned employees. As would be expected, not all employees were satisfied, but there did not appear to be any ongoing problems with reprisals against employees who had filed concerns. Also, there did not appear to be any othet recent situations where employees brought their concerns first to the media or external organizations.

The investigation team could not interview the employees to determine their logic. Therefore, the investigation team could not determine if the employees acted from a lack of confidence in the employee concerns system. However, a possibility is that the employees believed that management's action in turning the sampler off was so serious that either nothing would ever be done to resolve the issue or that reprisals would be inevitable.

The investigation team did not see evidence of a breakdown in the employee concerns system and made no recommendations in this regard. 


\section{Recommendations}

\section{A. Recommendations for $\mathbf{R L}$ and Contractors}

1. RL and its contractors should each review the facts and causes of this event with appropriate personnel. The review should emphasize the importance of assuring that only the correct authorities approve documents or authorize actions. The review should also emphasize the importance of assuring that worker and public perception is taken into account when resolving health, safety, and environmental issues.

2. RL and its contractors should review the method used to identify work that may be unusually sensitive. The identification process should assure that appropriate managers are consistently aware of significant issues, such as by working with the $\mathrm{RL}$ and contractor offices for external affairs.

3. $\mathrm{RL}$ and its contractors should review how they evaluate waste and other material coming to the Hanford Site that may be of an unusually sensitive nature. The evaluation process should assure that appropriate organizations review the material coming to the Site and inform appropriate senior managers and public involvement specialists.

\section{B. Recommendations for RL}

1. RL should issue a directive that describes the process for managing Notices of Construction.

2. RL should issue a directive, or modify an existing directive, to describe the process for establishing need-to-know for access to classified information.

3. RL should clarify its policy for signature authority and review the clarified policy with its personnel. Wherever individual contributor personnel are granted authority to sign external documents, this authority should be documented in writing.

4. RL should reevaluate its information system for reporting activities to senior management. It should assure that sensitive work is identified and accurately described to senior management. 
5. RL-EAP should continue to improve its resources for following air permitting issues.

6. RL should assure that DOE O 425.1, Startup and Restart of Nuclear Facilities, is implemented promptly by all Hanford contractors.

7. RL should revise RLID 425.1 to provide clear implementation of the requirements of DOE 0 425.1. In particular, it should assure that clear requirements are specified for contractor readiness assessments for startup of program activities, as described in section 2.a.(2) of the Contractor Requirements Document.

8. $\mathrm{RL}$ should continue to work on improving its communications with regulatory authorities.

9. RL should review the way that it is complying with the assignments of responsibility specified in the FRAM. It should take action to either assure that the divisions comply with the FRAM or change the FRAM.

\section{Recommendations for PNNL}

1. PNNL should review its policy and practices with regard to pre-operational assessments. It should assure that the degree of rigor and resources applied to pre-operational assessments are commensurate with safety, regulatory, and financial risks, as well as risk to the reputation of the Battelle. PNNL should develop a procedure that reflects the results of the review.

2. PNNL should evaluate its control over work performed on the Hanford Site in non-PNNL facilities. It should develop formalized processes to assure that work is adequately controlled. The process should assure that facility requirements, such as for ALARA reviews and USQ evaluations are identified early.

3. PNNL should review its implementation of DOE occurrence reporting requirements. It should act to assure that value basis reporting is performed where required.

4. PNNL should review its use of the "Prep and Risk" form. The review should determine how accuracy of the completed forms can be improved. For example, PNNL should assure that the question regarding the potential for adverse public reaction is answered correctly and that follow-up is appropriate.

5. PNNL should revise the guidance for question no. 44 of the electronic "Prep and Risk" form. If the question is answered "yes," the user should be directed to the public involvement specialists, rather than the Legal Department. Also, appropriate emphasis should be placed on the option of performing an independent review when the question is marked, "yes." 


\section{Recommendations for FDH}

1. FDH and RL-TPD should review the approach they are taking to configuration management of safety basis documents. Where appropriate, documents like the SAR and FEMP should be updated to reflect current facility configuration.

2. FDH should assure that facility changes in the Building 324 facility, including operational configuration changes, are properly screened for USQs. 
$4 / 18 / 96$
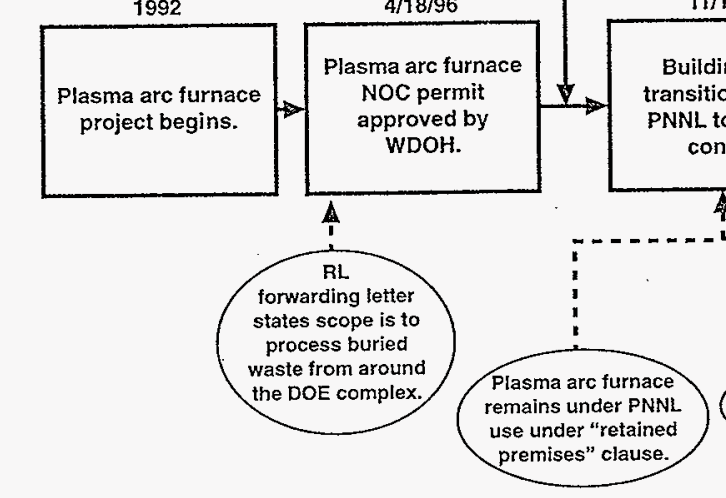

4

$11 / 1 / 96$

Building 324 ansitions from
PNL to BWHC control. control.
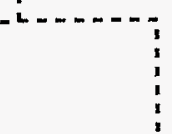

Contributing Cause:

Coniguation control LTA.

i

Continuous tritium

monitoring being
performed.

$$
\text { A }
$$

No discussion of

required tritium sampling
in "Requirements" section

$$
\text { of }
$$

FEMP description section states both continuous
sampling and continuous manitoring for tritium were

occurring.

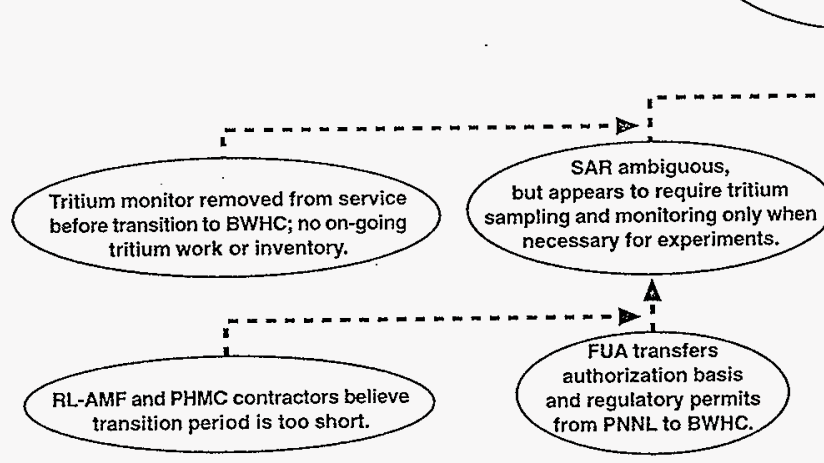

4

weapons

sma arc furnace egins losing waste redirects to

treatment of

components.

A

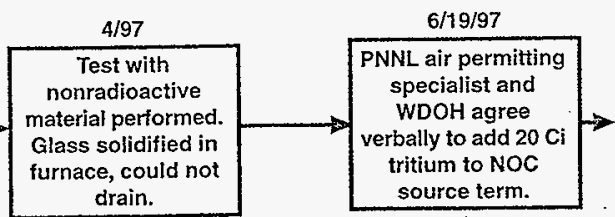

$7 / 97$

Another test with nonradioactive material fails. Test with radioactive material delayed. $A$

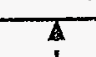

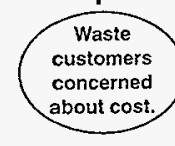

drain. 1

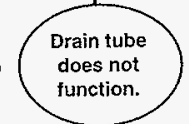

A

Root Cause: System

No occurrence

design and development (report written; value

A

$$
\text { A }
$$

No formal Hanford

process for NOC

generation or
modification.

$$
\frac{A}{1}
$$

assessment
considered or

performed.

source not defined

source not defined
in NOC modification
(weapons product

(weapons product

$$
\text { vs. wast }
$$

Contributing Cause:

rask assignment LTA.
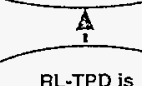

RL-TPD is
responsible for responsible for
Building 324.
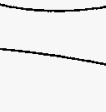

The following conditions prevailed during the period of this event:

There was no formal Hanford process for managing NOCs.

RL organizations were not adhering closely to the roles and responsibilities defined in the FRAM. adiness assessment requirements of DOE $O 425.1$

for program activities. PNNL did not have a formal process for pre-operational assessments to assure that all issues would be identified and resolved.

The

as cescribed in the FRAM.

- The Building 324 FEMP and SAR did not accurately reflect the configuration of stack tritium monitoring equipment PNNL was not exercising adequate control over activities conducted on the Hanford Site in non-PNNL facilities.
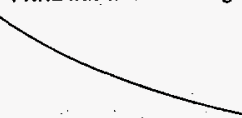


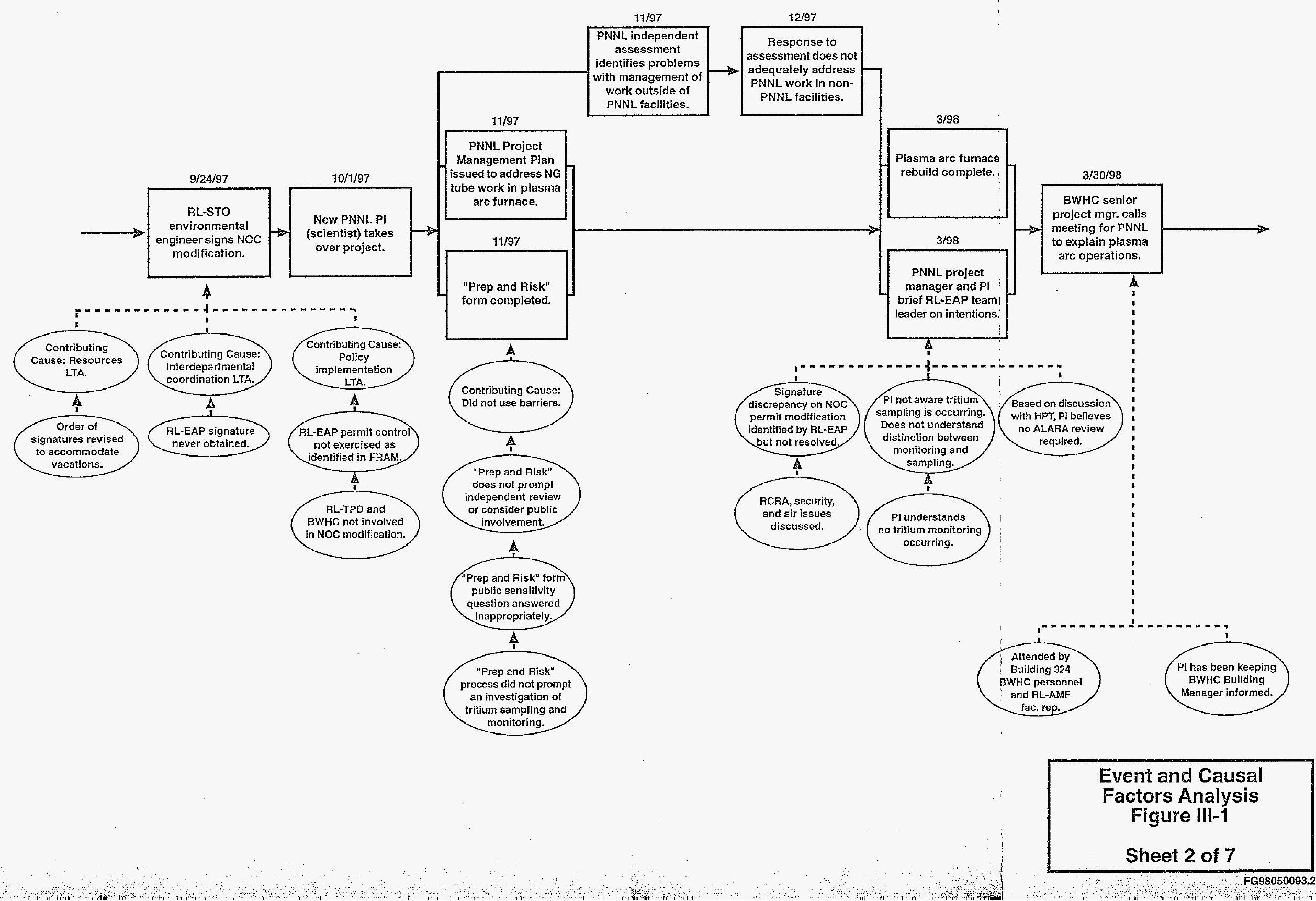




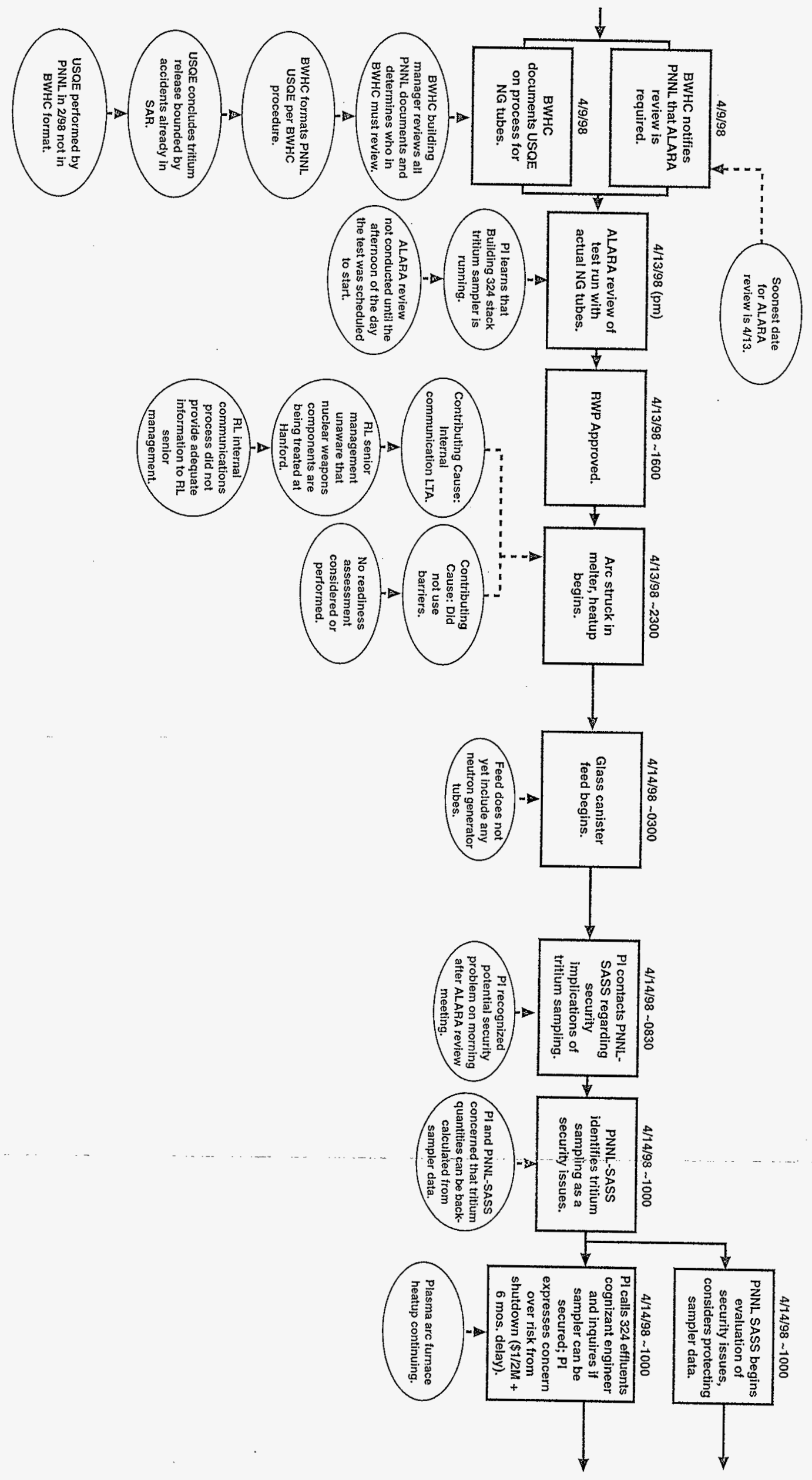




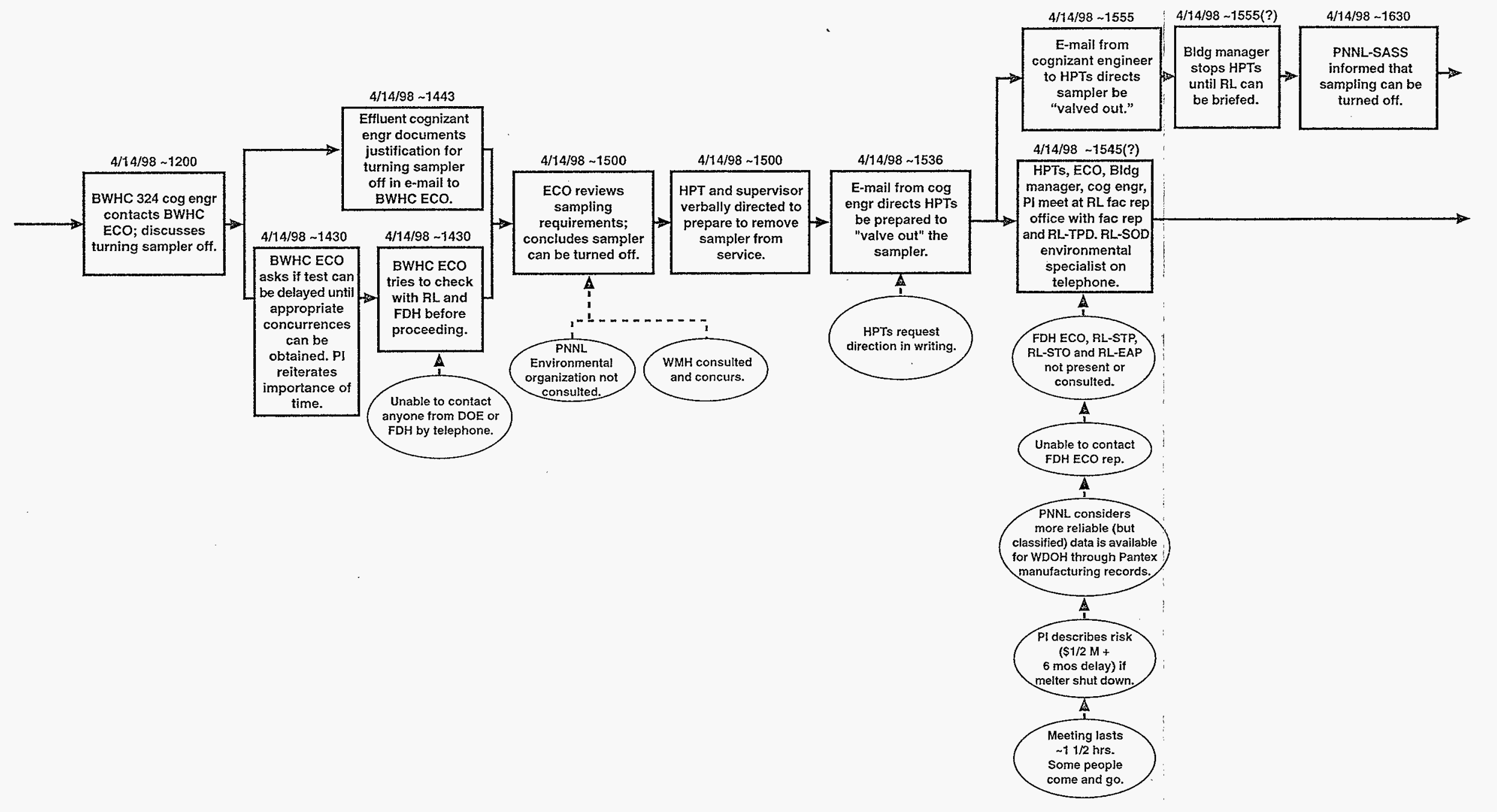

\section{Event and Causal Factors Analysis Figure III-1}

Sheet 4 of 7 


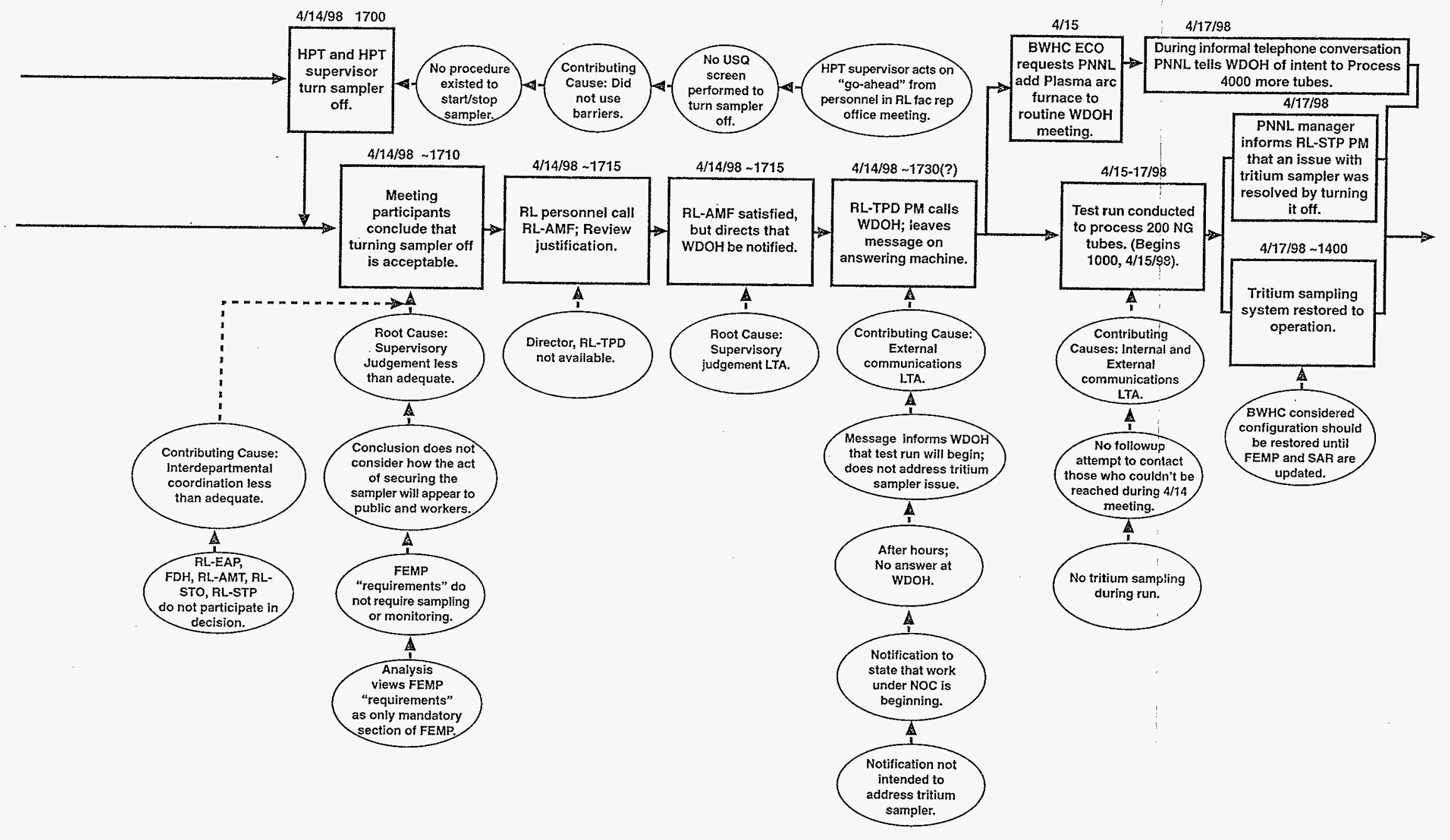

Event and Causal

Factors Analysis Figure III-1

Sheet 5 of 7 


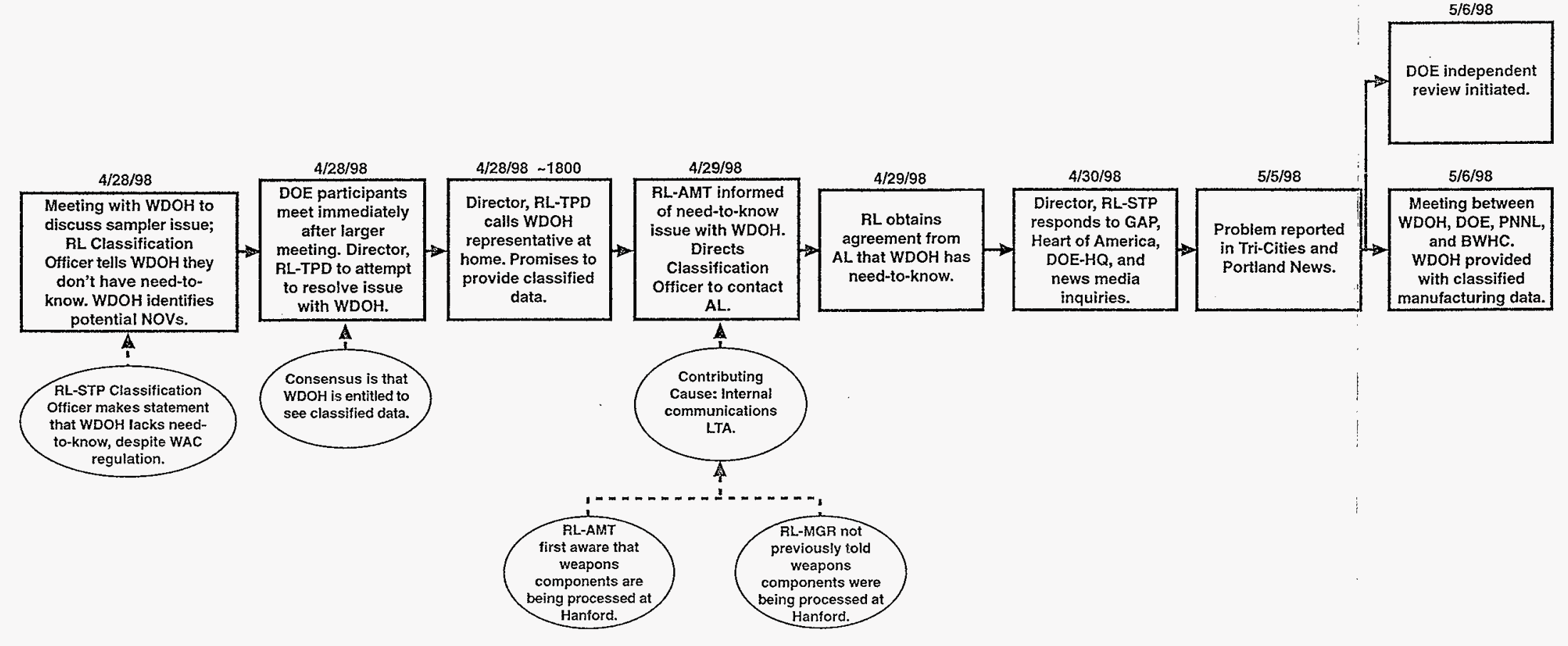

\begin{tabular}{|c|c|c|c|c|c|}
\hline \multicolumn{6}{|c|}{ Acronyms: } \\
\hline & Albuquerque Operations Office & LTA & Less Than Adequate & RL-AMF & Assistant Manager for Facility Transition \\
\hline BWHC & B\&W Hanford and Company & NG & Neutron Generator & RL-AMT & Assistant Manager for Science and Technology \\
\hline & Division Director & NOC Permit & Notice of Construction & RL-EAP & Environmental Assurance, Permits and Policy Division \\
\hline & Environmental Compliance Officer & & Notice of Violation & RL-MGR & Manager, Fichland Operations Office \\
\hline Fac Rep & Facility Representative & $\mathrm{PI}$ & PNNL Principle Investigator (Scientist) & RL-SAS & Safeguards and Security Division \\
\hline $\mathrm{FDH}$ & Fuor Daniel Hanford Company & PM & Program Manager & RL-SOD & Site Operations Division \\
\hline FEMP & Facility Environmental Monitoring Plan & PNNL & Pacific Northwest National Laboratory & RL-STO & Science and Technology Operations Division \\
\hline FRAM & Functions, Responsibilities, and Assignments Matrix & PNNL-SASS & Safeguards and Security & RL-STP & Science and Technology Programs Division \\
\hline FUA & Facility Use Agreement & QAPP & Quality Assurance Program Plan & RLLTPD & Transffion Programs Division \\
\hline $\begin{array}{l}\text { GAP } \\
\text { HPT }\end{array}$ & $\begin{array}{l}\text { Government Accountability Project } \\
\text { Health Physics Technician }\end{array}$ & $\begin{array}{l}\text { RCAA } \\
\text { RL }\end{array}$ & $\begin{array}{l}\text { Resource Conservation and Recovery Act } \\
\text { Richland Operations Office }\end{array}$ & $\begin{array}{l}\text { USOE } \\
\text { WDOH }\end{array}$ & $\begin{array}{l}\text { Unreviewed Safety Question Evaluatition } \\
\text { Washington State Depariment of Health }\end{array}$ \\
\hline
\end{tabular}

Event and Causal

Factors Analysis

Figure III-1

Sheet 7 of 7 

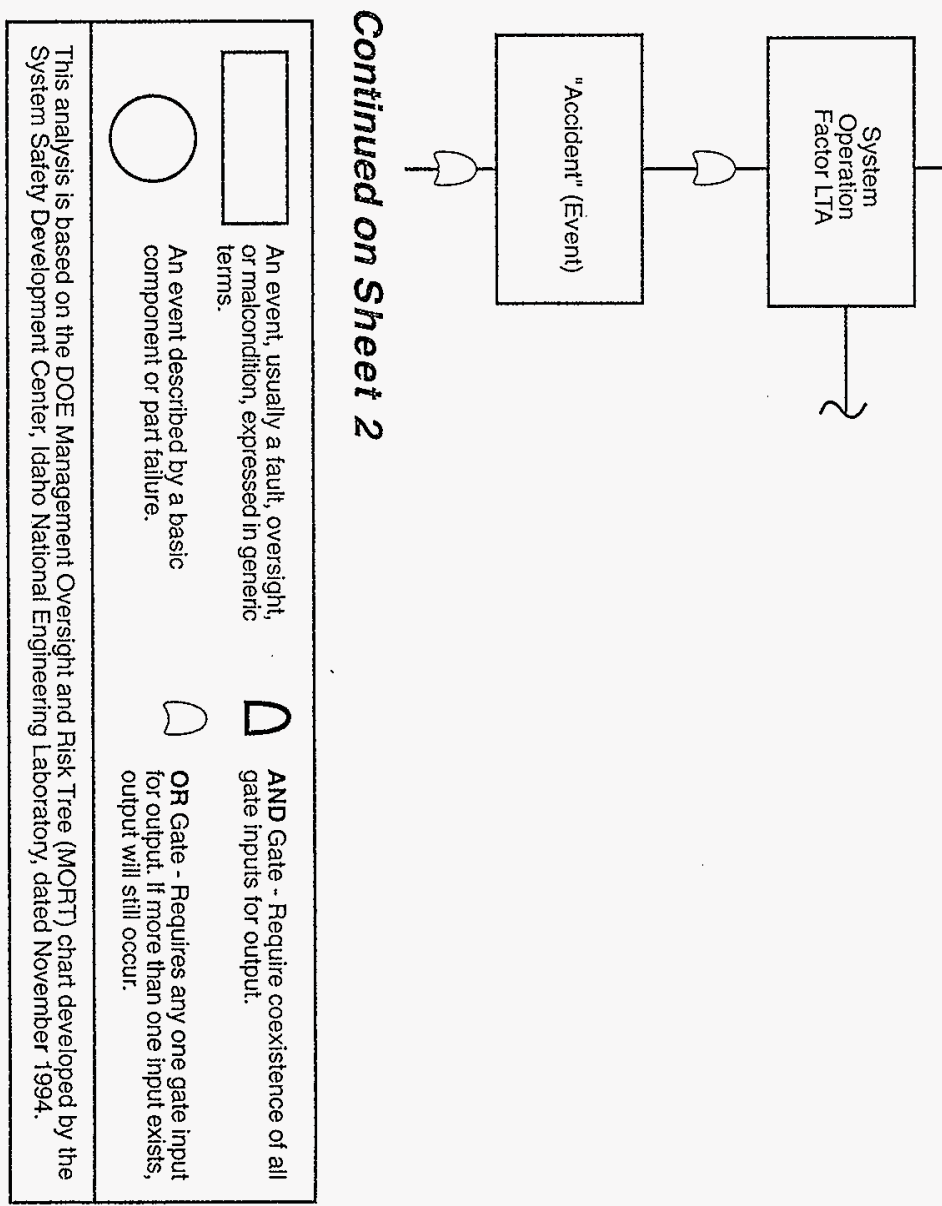

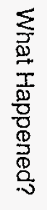
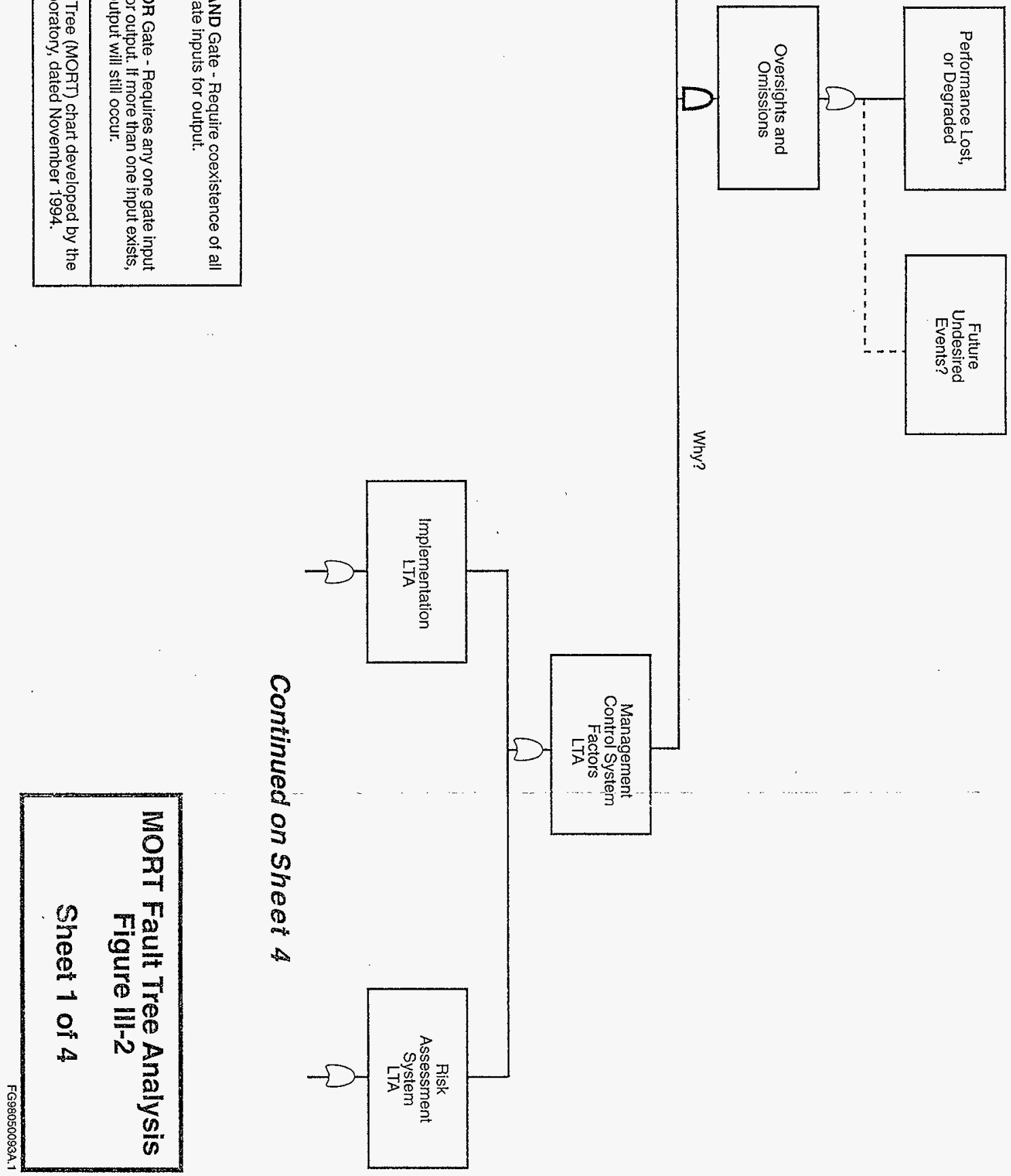


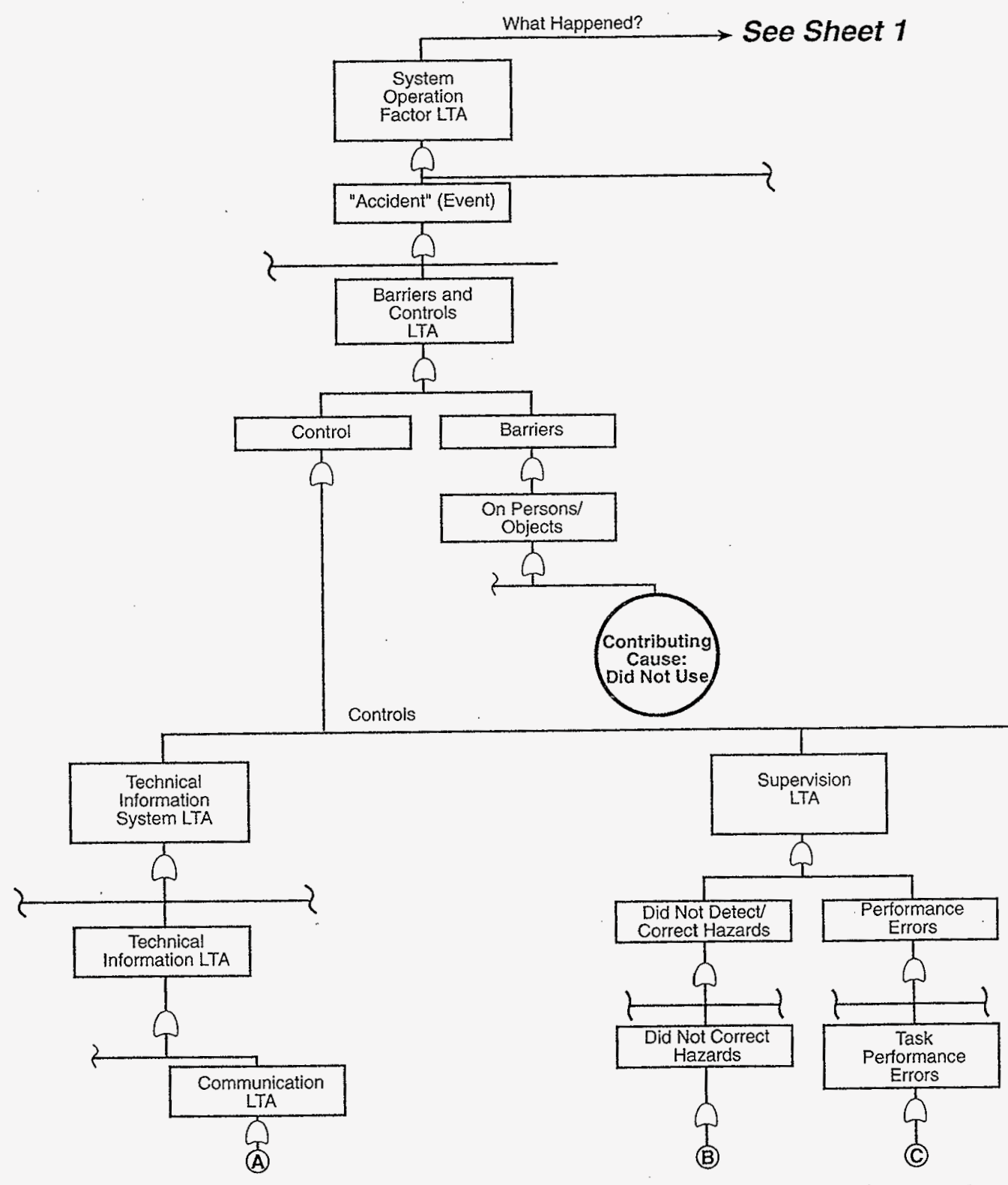

MORT Fault Tree Analysis

Figure III-2

Sheet 2 of 4

Continued on Sheet 3

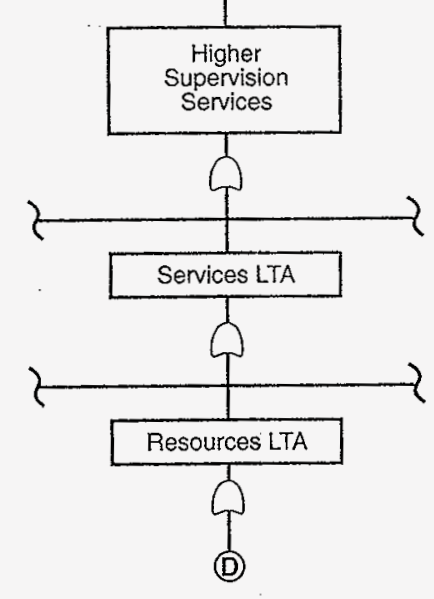


MORT Fault Tree Analysis

Figure III-2

Sheet 3 of 4

See Sheet 2
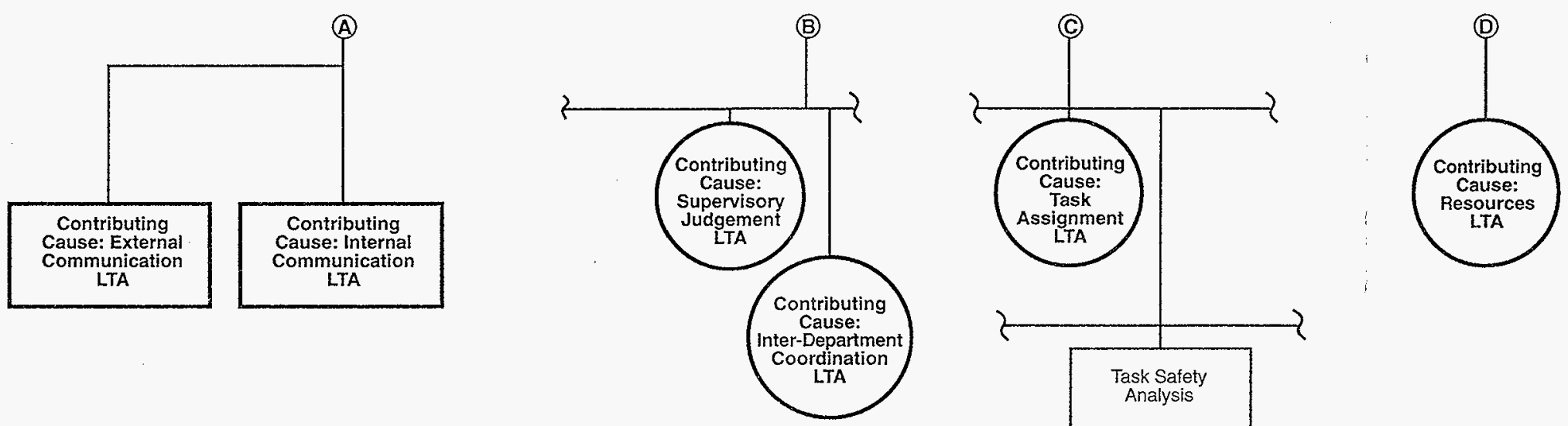
See Sheet 1

Why?

MORT Fault Tree Analysis Figure III-2

Sheet 4 of 4

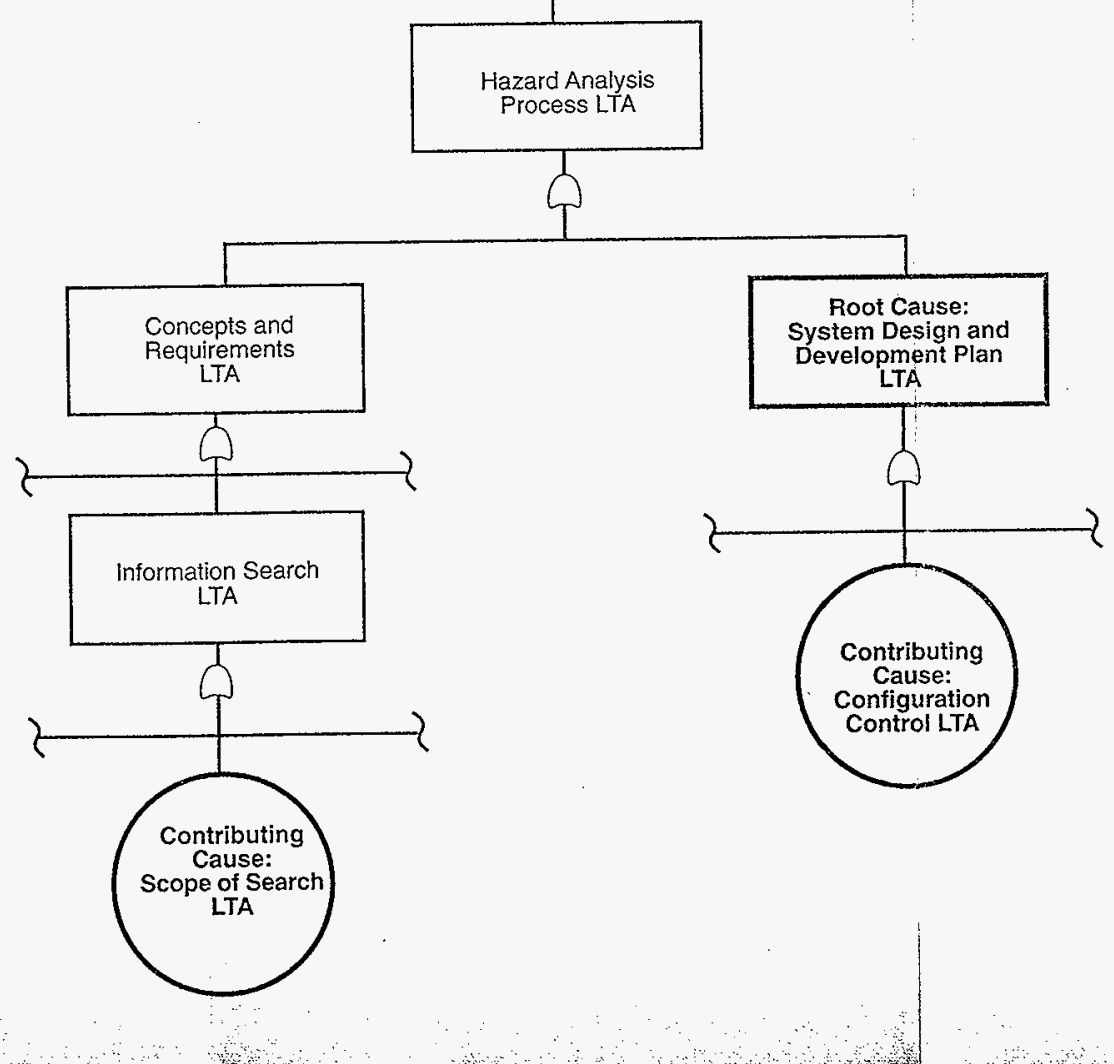




\section{Signatures}

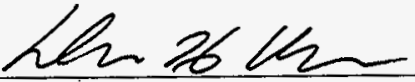

David H. Brown, Lead Investigator

Certified Accident Investigator

Performance Assessment Division

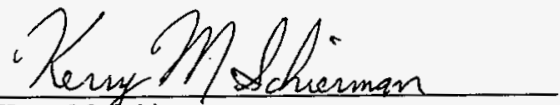

Kerry Meschierman,

Investigator

Waste Operations Division

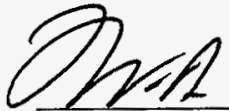

W. Don Seaborg,

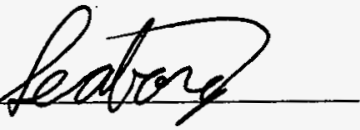

Investigator

Site Operations Division

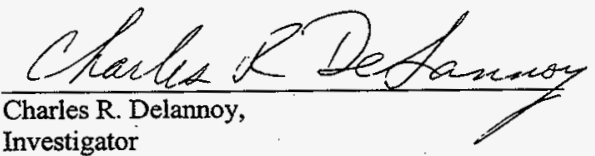

Performance Assessment Division 


\section{Appendix A}

\section{Table of Acronyms}

$\begin{array}{ll}\text { AL } & \text { Albuquerque Operations Office } \\ \text { BWHC } & \text { B\&W Hanford and Company } \\ \text { DOE } & \text { U. S. Department of Energy } \\ \text { ECO } & \text { Environmental Compliance Officer } \\ \text { FDH } & \text { Fluor Daniel Hanford Company } \\ \text { FEMP } & \text { Facility Environmental Monitoring Plan } \\ \text { FFTF } & \text { Fast Flux Test Facility } \\ \text { FRAM } & \text { Functions, Responsibilities, and Assignments Matrix } \\ \text { FUA } & \text { Facility Use Agreement } \\ \text { GAP } & \text { Government Accountability Project } \\ \text { NOC } & \text { Notice of Construction } \\ \text { NOV } & \text { Notice of Violation } \\ \text { PI } & \text { PNNL Principle Investigator (Scientist) } \\ \text { PNNL } & \text { Pacific Northwest National Laboratory } \\ \text { PNNL-SASS } & \text { Safeguards and Security } \\ \text { RL } & \text { Richland Operations Office } \\ \text { RL-AMF } & \text { Assistant Manager for Facility Transition } \\ \text { RL-AMT } & \text { Assistant Manager for Science and Technology } \\ \text { RL-EAP } & \text { Environmental Assurance, Permits and Policy Division } \\ \text { RL-MGR } & \text { Manager, Richland Operations Office } \\ \text { RL-SAS } & \text { Safeguards and Security Division } \\ \text { RL-SOD } & \text { Site Operations Division } \\ \text { RL-STO } & \text { Science and Technology Operations Division } \\ \text { RL-STP } & \text { Science and Technology Programs Division } \\ \text { RL-TPD } & \text { Transition Programs Division } \\ \text { S/RDs } & \text { Standards/Requirements Implementation Documents } \\ \text { USQ } & \text { Unreviewed Safety Question } \\ \text { WDOH } & \text { Washington State Department of Health }\end{array}$

